\title{
The Potential Role of Cytokines and growth factors in the pathogenesis of Alzheimer's Disease
}

Gilbert Ogunmokun ${ }^{1}$, Saikat Dewanjee ${ }^{2}$, Pratik Chakraborty ${ }^{2}$, Chandrasekhar Valupadas ${ }^{3,4}$ Anupama Chaudhary $^{5}$, Viswakalyan Kolli ${ }^{6}$, Uttpal Anand ${ }^{7}$, Jayalakshmi Vallamkondu ${ }^{8}$, Parul Goel ${ }^{9}$, Hari Prasad Reddy

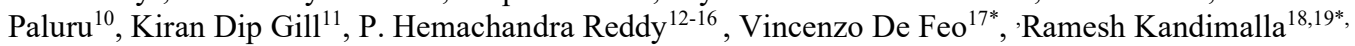

${ }^{1}$ The University of Texas Health Science Center at Houston (UTHealth) School of Public Health, Houston, Texas, USA

${ }^{2}$ Advanced Pharmacognosy Research Laboratory, Department of Pharmaceutical Technology, Jadavpur University, Kolkata 700032, India

${ }^{3}$ Professor, Internal Medicine \& Medical Superintendent, MGM Hospital, Warangal, India

${ }^{4}$ In charge Medical Superintendent, KMC Superspeciality Hospital, Warangal, India

${ }^{5}$ Orinin-BioSystems, LE-52, Lotus Road 4, CHD City, Karnal, Karnal, Haryana -132001, India

${ }^{6}$ Professor, Department of Biochemistry, GITAM Institute of Medical Sciences and Research, Visakhapatnam, India

${ }^{7}$ Department of Life Sciences and the National Institute for Biotechnology in the Negev, Ben-Gurion University of the Negev, Beer-Sheva, Israel

${ }^{8}$ National Institute of Technology, Warangal 506004, Telangana, India

${ }^{9}$ Department of Biochemistry, Maharishi Markandeshwar Institute of Medical Sciences \& Research, Mullana, Ambala, India

${ }^{10}$ Sri Krsihnadevaraya University, Anantapur, Andhra Pradesh, India

${ }^{11}$ Department of Biochemistry, Posgraduate Institute of Medical Education \& Research (PGIMER), Chandigarh, India

${ }^{12}$ Texas Tech University Health Sciences Center, Lubbock, TX, USA

${ }^{13}$ Neuroscience \& Pharmacology, Texas Tech University Health Sciences Center, Lubbock, TX, USA

${ }^{14}$ Departments of Neurology, School of Medicine, Texas Tech University Health Sciences Center, Lubbock, TX, USA

${ }^{15}$ Public Health Department of Graduate School of Biomedical Sciences, Texas Tech University Health Sciences Center, Lubbock, TX, USA

${ }^{16}$ Department of Speech, Language and Hearing Sciences, School Health Professions, Texas Tech University Health Sciences Center, Lubbock, TX, USA

${ }^{17}$ Department of Pharmacy, University of Salerno, 84084 Fisciano, Italy

${ }^{18}$ Applied Biology, CSIR-Indian Institute of Technology, Uppal Road, Tarnaka, Hyderabad 50000, Telangana, India

${ }^{19}$ Department of Biochemistry, Kakatiya Medical College, Warangal 506007, Telangana, India

*Corresponding authors: defeo@unisa.it; ramesh.kandimalla@gmail.com

Abstract: Alzheimer's disease (AD) is a neurodegenerative disorder characterized mainly by the gradual decay in neuronal function as a consequence of diverse degenerating events primarily including mitochondria dysfunction and cascades of neuro-immune reactions. Besides the acquired harmful reactive oxygen species (ROS), neurotoxins, and amyloid-beta $(\mathrm{A} \beta)$ and TAU pathologies in neurons, accumulating evidence with time underlined the roles of cytokines and growth factors in the $\mathrm{AD}$ pathogenesis. It may help us in evaluating the propensities and specific mechanism(s) of cytokines and factors impacting neuron upon apoptotic decline. Proinflammatory cytokines often induce inflammation in AD and AD-like pathogenesis in response to the apoptotic scenarios where some growth factors are involved in cytokinetic reactions to activate microglia and causing inflammation in AD. In this report, we comprehensively reviewed role of cytokines and chemokines in immune response to $\mathrm{AD}$ and neuropsychiatry. We provided insights into the neuroinflammation and the role of diverse factors including the pro-/anti-inflammatory cytokines, APP, TAU phosphorylation, glycation end products, complement system and the role of glial cells. Also, we discussed the pathogenic and protective role of macrophage migration inhibitory factors, choroid plexus-, neurotrophic- and hematopoietic -related growth factors in $\mathrm{AD}$. We further shed light on the availability and accessibility of the cytokines across the blood-brain barrier in the AD pathophysiology. Taken together, emerging role of these factors in AD pathology emphasized the importance of building novel strategies for an effective therapeutic/neuropsychiatric management of AD in clinics.

Keywords: Alzheimer's disease; cytokines; chemokines; neuroinflammation; neurotrophic factors; pathophysiology; Blood brain barrier; mild cognitive impairment; brain health; therapeutics 
Abbreviations: AD: Alzheimer's disease; BBB: Blood brain barrier; MCI: mild cognitive impairment; ROS: reactive oxygen species, CNS: central nervous system

\section{Highlights:}

1. Cytokines and growth factors play crucial roles in the AD pathogenesis.

2. Macrophage migration inhibitory factors, choroid plexus-, neurotrophic- and hematopoietic -related growth factors have intrinsic functions in the AD pathogenesis.

3. Cytokines and growth factors impact the molecular processes in neurons necessary for homeostasis in cognitive mechanisms.

\section{Introduction}

Neurodegeneration has been a puzzle gradually elucidating with the progress of ample research and the investigation on dementia and progressive cognitive decline. Dementia is understood as the decline in memory and other fundamental cognitive functions. One such disease of focus is Alzheimer's disease (AD). AD is the most occurring neurodegenerative disease of the world characterized chiefly by the gradual death of neurons consequential of degenerating mitochondria that decay in a cascade of neuro-immune reactions [1]. The accumulation of harmful reactive oxygen species (ROS), neurotoxins, and TAU pathologies that result in neurofibrillary tangles consisting of TAU protein and including amyloid-beta (A $\beta$ ) which eventually form plaques after accumulation from the aberrant processing of its precursor protein; amyloid precursor protein (APP).

Cytokines are non-structural proteins within the molecular weight range of 8000 40,000 Da. In general, they can be described as inflammatory peptides aiding the immune defense response of the body. Almost all nucleated cells are capable of synthesizing them. These cells, in turn, can respond to cytokines too. Though cytokines cannot be tagged with a particular amino acid sequence motif, they can be grouped into certain classes based on their 
biological activities. The vast spread of biological activity of cytokines ranges from cell proliferation to apoptosis, from cell differentiation to inflammatory responses. Cytokines are also termed lymphokines since they are primarily involved in the differentiation of different types of $\mathrm{T}$ lymphocytes viz. $\mathrm{T}$ helper cells and $\mathrm{T}$ regulatory cells from undifferentiated cells [2]. Many of these proteins e.g. interleukins (ILs), interferons (INFs), tumor necrosis factors (TNFs), and certain growth factors are produced by neurons and glial cells of the brain. Levels of IL-1 $\alpha$, IL-1 $1 \beta$, IL-6, TNF- $\alpha$, IFN- $\alpha$, macrophage colony-stimulating factors, IFN- $\alpha$ and IL-8 receptor type B are enhanced in blood and cerebrospinal fluid (CSF) in AD patients. Nerve growth factors (NGF), growth-promoting properties of APP, vascular endothelial growth factor (VEGF) play vital roles in the pathophysiology of AD. Growth factors, proteins by nature support the survival of cells within the nervous system. They are vital players for the proper development of the brain. In the central and peripheral nervous systems, they stimulate axonal growth and regulate the growth of different kinds of cells.

AD is named after German psychiatrist and neurologist Alois Alzheimer [3]. In 1906, the doctor noted some peculiar findings in the brain of a patient who expired after suffering from memory loss, disorientation, paranoia, and unpredictable behaviors. AD causes a gradual decline in cognitive processes (Table 1). AD, by nature, is an insidious, progressive, degenerative disorder. With the improvements in medical science, life expectancy has increased a lot. Hence, the occurrence of degenerative disorders like AD is also increasing with the increase in the geriatric population. AD invariably starts from the hippocampus (responsible for new memory generation) making anterograde amnesia a primary symptom of the disease. As neurofibrillary tangles start to spread outward towards the frontal lobe, dementia is followed by speech problems, mood imbalance, inability in decision making progressively [4]. Genes like senilins, SORL1, APP, and ApoE4 are involved in the onset and development of $\mathrm{AD}$ [4]. Early onset $\mathrm{AD}$ is generally familial while late onset $\mathrm{AD}$ is largely 
related to SORL1. From the viewpoint of pathophysiology, AD is characterized by intracellular neurofibrillary tangles and extracellular senile plaques.

To identify and elucidate the role of cytokines and their co-associating factors, such as growth factors, in the immune system and in response to the pathogenesis of $\mathrm{AD}$, is key understanding to increase the potentials for therapeutic intervention. Current review aims to analyze research data, prior AD-related research, and affiliations between connected fates of inflammatory and immune responses of $\mathrm{AD}$, to help identify the role of cytokines and key growth factors implicated in $\mathrm{AD}$.

\section{Immune response in AD: role of cytokines}

It is now understood that $\mathrm{A} \beta$ and TAU pathologies are the main driving factors in the escalation of neurodegeneration and progression of $\mathrm{AD}$. The role of the immune system in central nervous system (CNS) pathologies such as cell-mediated immunity in the reaction of neurons to the accumulation of $A \beta$ plaques and TAU neurofibrillary tangles are innate in nature. In the initiating events of neurodegeneration, the immune reactions which trigger macrophages, M2 and sometimes M1 are activated [5]. These macrophages secrete chemical messengers in interneuronal communications and develop autoimmune neurotoxicity including those reactions that lead to neuroinflammation and escalation of AD. The immune system employs chemical messengers known as cytokines, which play a major role in immune responses following the activation of microglia in the pathology of AD. These messengers determine the mechanisms and reactions that take place in the immune system in response to abnormal changes in the neurons triggering the recruitment of other defensive cells including neutrophils and macrophage progenitor cells already circulating in the blood post-hematopoiesis and through blood-brain barrier (BBB). 
In the case of $\mathrm{AD}, \beta$ amyloids originating from APP trigger the rest of the pathologies. $\beta$ amyloids outside the neurons and neurofibrillary tangles inside the neurons make up for the development of $\mathrm{AD}[6,7] . \beta$ amyloids, in turn, produce immune response activating complement systems. In CNS, the immune system is programmed to functionally respond to pathological changes such as those presented by the progression of AD [5]. The immune system activation observed in $\mathrm{AD}$ is labelled as neuroinflammation [8]. Misfolded and aggregated proteins i.e. $\beta$ amyloids act through danger-associated molecular pathways (DAMP) to bind pathogen recognition receptors like CD14, CD36, CD36, $\alpha 6 \beta 1$, integrin, and toll-like receptors [9]. These, in turn, control functions of ROS, NO, IL-1 $\beta$ and TNF- $\alpha$. It has been shown experimentally that, contrary to antiquated conclusions about neuroinflammation being a mere pathological advent in the late onset of this dementia-related disease, neuroinflammation observed as expressed in mild cognitive impairment (MCI), early-onset and late onset $\mathrm{AD}$ are initiating events predominantly driven by the CNS resident immune cells, such as microglia and perivascular myeloid cells [8]. Genetic variants and transcription factors also determine the expression of activated microglia in the pathological environment. Damaging or degenerating neurons give off signals acting as a form of microglial control switch that stimulates microglia which could become cytotoxic from the reactive intermediates solicited such as pro-inflammatory cytokines [10]. Cytokines may act in an autocrine, paracrine or endocrine fashion. In response to a change in homeostasis, microglia must first be activated, changing it from a static to a primed state. Changes in infiltrating monocytes that support CNS immune response in the parenchyma and neuronal progenitor granule crossing of the BBB might be a hallmark for early detection of AD and propensity of inflammatory response and neurodegeneration [11]. Asymmetrical changes in serum and plasma levels of cytokines may indicate changes in early cytokine levels widely reported in 
macrophage precursor cells that may confer a greater risk of developing neurodegeneration and abnormal macrophage morphology.

\section{Role of cytokines and chemokines in neuropsychiatry}

The study of cytokines to understand the pathophysiology of neuropsychiatric disorders like dementia, anxiety, delirium has been pioneered by Dr. M. Maes who first linked the vegetative symptoms with enhanced presence of IL-1, IL-6 and haptoglobin [12]. Chemokines regulate the migration of microglia and the recruitment of astrocytes to sites of inflammation. Chemokines are upregulated at sites of $\mathrm{A} \beta$ plaques. $\mathrm{A} \beta$ mediated cell mediators such as monocytes also are responsible for the generation of IL-8, monocyte chemoattractant protein 1 (MCP1), macrophage inflammatory protein $1 \alpha$ and macrophage inflammatory protein (MIP) 1ß. Lipopolysaccharide stimulated astrocytes to secrete cytokines including IL- 6 and TNF- $\alpha$, activated astrocytoma cells secrete IL- 6 and IL-8 and monocytes secrete IL- 8 under the influence of A $\beta$ peptides [13]. Synergistic activity of cytokines has also been reported along with $\mathrm{A} \beta$ peptides e.g. TFN- $\gamma$ synergizes with $\mathrm{A} \beta$ to enhance secretion of TFN- $\alpha$ and reactive nitrogen species [14]. IL-1 $\beta$ displays proinflammatory actions via MEK $1 / 2$, JNK-activated $\alpha$-secretase cleavage and upregulated ADAM17/TACE pathway to increase sAPP $\alpha$ secretion [15]. On the contrary, IL-1 $\beta$ can also serve as an anti-amyloidogenic factor by decreasing sAPP $\beta$ and amyloidogenic A $\beta$ fragment levels by reducing $\beta$-secretase cleavage [16]. It was also suggested that increased $A \beta$ clearance by microglia in models of sustained IL-1 $\beta$ neuroinflammation could involve Th2 cytokines, such as IL-4 [17]. A feedback signalling loop between A $\beta$ and IL-1 $\beta$ was proposed in which $\mathrm{A} \beta$ can induce the production of IL-1 $\beta$ [18]. Migration of astrocytes to amyloid plaques is promoted by chemokines CCL2 and CCL3, which are released by activated microglial cells. 
Important pathways involved in the pathogenesis of $\mathrm{AD}$ include amyloid cascade hypothesis, TAU hypothesis, cholinergic hypothesis and excitotoxicity hypothesis. In the case of $\mathrm{AD}, \mathrm{CSF}$ dysfunction is noticed even before cognitive decline. Activities of mTOR cause vascular irregularities in the brain decreasing cerebral blood flow which in turn sets up cognitive decline. Amyloid cascade hypothesis identifies accumulation of A $\beta$ plaques at different areas of CNS and related changes as the principal factor behind the development of AD [19]. TAU hypothesis suggests hyperphosphorylation of TAU leading to neurofibrillary tangles instead of supporting axonal microtubules is instrumental in case of neurodegenerative disorders [20]. Cholinergic hypothesis focuses on symptoms of cognitive decline and presents malfunctioning of cholinergic neurons as a pathophysiological factor towards initiation of $\mathrm{AD}$ [21]. Excitotoxicity refers to the unprecedented death of nerve cells due to overstimulation of certain amino acid receptors [22]. A high concentration of glutamates activates N-methyl-d-aspartate and $\alpha$-amino-3-hydroxy-5-methylisoxazole propionic acid receptors. As a result, voltage gated calcium allows the entry of extracellular calcium into cells. Hindrance in neuronal energy metabolism leads to cell death.

\section{Neuroinflammation}

Inflammation is the response of our body system to eliminate both sources of cell injury along with the cell and tissue debris originating from the insult. The immune system activation observed in $\mathrm{AD}$ is labelled as neuroinflammation. Though classical signs of inflammation like swelling, heat and pain are absent in brain inflammation, it characteristically involves increased monocytes and glial macrophage cells [23]. In the initiating events of neurodegeneration, the immune reactions which are involved that trigger macrophages, M2 and sometimes M1 are activated [24]. These macrophages secrete chemical messengers in interneuronal communications and develop autoimmune neurotoxicity including those reactions that lead to neuroinflammation and the escalation of AD. Activated 
cells strongly produce inflammatory mediators such as proinflammatory cytokines, chemokines, macrophage inflammatory proteins, monocyte chemo-attractant proteins, prostaglandins, leukotrienes, thromboxanes, coagulation factors, ROS (and other radicals), nitric oxide, complement factors, proteases, protease inhibitors, pentraxins and C-reactive protein. Upregulated immunoinflammatory events play important roles in the pathogenesis of AD.

Chronic neuroinflammation (immune response to the formation of $\mathrm{A} \beta$ peptides and neurofibrillary tangles) is characterized by persistent activation of microglia and release of inflammatory mediators. Hence, an inflammatory cycle is perpetuated since microglia and astrocytes are constantly activated, leading to a further increase in the levels of cytokines and chemokines. These mediators, in turn, alter APP processing encouraging the formation of amyloid plaques. These alterations also result in reduced production of neuroprotective sAPP $\alpha$. Senile plaques activate the complement system resulting in inflammation within CNS. Thus, neuroinflammation-mediated tissue damage initiates the degeneration process. During the early stages of $\mathrm{AD}$, neuroinflammation leads to the entry of peripheral nervous system (PNS) cells with chemokine receptors into the brain crossing BBB [25]. As a result of A $\beta$ deposition, chemokines e.g. CCL2, IL-8, CXCL10, CCL5 are released from PNS.

Amyloid plaques containing dystrophic neuritis, activated microglia and reactive astrocytes, along with released inflammatory mediators contribute to neuronal dystrophy. Inflammatory mediators and activated glial cells together kill neighbouring neurons and encourage amyloidogenic processing of APP. The inability of CNS phagocytes to clear amyloid plaques and upregulated formation of plaques as a result of chronic neuroinflammation play instrumental roles in $\mathrm{AD}$ [26]. In a cohort study, Taipa et al (2019) reported elevated levels of eotaxin, IL-1 receptor antagonist (IL-1ra), IL-4, IL-7, IL-8, IL-9, IL-10, IL-15, TNF- $\alpha$, granulocyte colony-stimulating factor (GCSF), MCP1 and platelet- 
derived growth factor in CSF of AD patients in comparison with non-demented controls. The same study also reported inverse relations between CSF levels of IL-1 $\beta$, IL-4, IL-6, IL-9, IL17A, IFN- $\gamma$, basic fibroblast growth factor (basic FGF/ FGF2), granulocyte colonystimulating factor, granulocyte-macrophage colony-stimulating factor, macrophage inflammatory proteins- $1 \beta$ and $\mathrm{AD}$ progression [27].

\subsection{Proinflammatory cytokines}

Cytokines are secreted by glial cells around A $\beta$ plaques. Disturbances in inflammatory and immune pathways in $\mathrm{AD}$ have been strongly associated with altered levels of some acutephase proteins and proinflammatory cytokines in the blood, CSF, and AD brains. Peptide A $\beta$ itself can induce the expression of several proinflammatory cytokines such as IL-1 $\beta$, IL-6, TNF- $\alpha$ and IFN- $\gamma$ by glial cells. Proinflammatory cytokines like macrophage migration inhibitory factor (MMIF), YKL40, TNFs, and their receptors, sTREM2 are clearly engaged in TAU pathology and in the aging process [28]. IL-15, MCP-1, VEGFR-1, sICAM1, sVCAM1, and VEGF-D are found to be associated with TAU pathology and correlate with CSF TAU level [29]. Proinflammatory cytokines induce indoleamine 2,3 dioxygenase to increase blood levels of quinolinic acid, a neurotoxic factor [30].

High levels of proinflammatory cytokines, such as IL-1 $\beta$, IL-6, and TNF- $\alpha$, have been detected in the brain of $\mathrm{AD}$ subjects [31]. Proinflammatory molecules produced by the reactive astrocytes can elevate the expression of secretases in neurons, enhancing the production of $A \beta$ and activating microglia to produce inflammatory factors [32]. In transgenic mice model, proinflammatory cytokines viz. IL-1 $\beta$, TNF- $\alpha$, IL-6, IL-12 and IL23 have been found to correlate with amyloid load [33].

IL- $1 \alpha$ and IL-1 $\beta$ initiate cell activation upon binding with cell membrane receptors. Elevated level of IL-1 $\beta$ is a characteristic feature of brain parenchymal cells immediately 
after injury [34]. IL-1 hastens neuronal degeneration by increasing the production of IL-6 and the activity of iNOS. In addition to that, IL-1 is also responsible for enhanced acetylcholinesterase activity, activation of astrocytes and microglial cells, expression of S100ß, production of macrophage colony-stimulating factor (MCSF) and further additional production of IL-1. IL-6 is a major player in host inflammatory response. IL-6 displays neurotrophic effects by activating microglia, promoting astrogliosis and stimulating the production of acute-phase proteins. IFN- $\gamma$ induces activities of TNFs and NO. TNF- $\alpha$ centrally regulates cytokine activities during inflammatory response through regulating an autocrine cascade of production of IL- 1 and TNF- $\alpha$ from glial cells. In the AD brain, IL-1 regulates APP processing. In an experiment, rat cortical glia cells presented themselves with increased IL-6 mRNA on being exposed to the first 105 carboxy-terminal amino acids of APP [35]. Dose-dependent increments are observed in levels of IL-1, IL-6, TNF- $\alpha$, MIP-1 $\alpha$ and MCP-1 in glial cells on exposure to $\mathrm{A} \beta$ peptides [36].

\subsection{Anti-inflammatory cytokines}

While IL-1ra, IL-4, IL-6, IL-10, IL-11, IL-13, TGF- $\beta$ act as anti-inflammatory cytokines, specific receptors for IL-1, TNF- $\alpha$, and IL-18 act as inhibitors of proinflammatory cytokines. Anti-inflammatory cytokines belonging to Th2 and Th3 cell subsets exert a protective effect against AD by counteracting the effects of proinflammatory cytokines [9]. TGF- $\beta$, produced by Th3 cells is capable of ameliorating $\mathrm{A} \beta$-induced cytotoxicity both in vivo and in vitro while deficiency of TGF- $\beta 1$ promotes accumulation of $A \beta$ peptides and formation of neurofibrillary tangles [37]. Dysregulation of the balance between proinflammatory and antiinflammatory cytokines in the favour of proinflammatory cytokines lead to a cycle of further cytokine production, cytokine synergism and cellular activation ultimately amplifying and worsening neuroinflammatory conditions. 
IL-4, IL-10 and IL-13 can suppress proinflammatory cytokine genes e.g. IL-1, TNF and chemokines'. IL-1ra directly antagonizes the activities of IL- $1 \alpha$ and IL- $1 \beta$ by competitive inhibition. Experimental results suggest that IL-1ra suppresses IL-1 $\beta$-induced TNF- $\alpha$ production and iNOS expression in astrocytes by preferentially binding with IL-1R1[38]. In addition to protecting against IL-1 $\beta$ induced neurotoxicity, IL-1ra also attenuates neuronal damage caused by ischaemic excitations. IL-4 can suppress proinflammatory cytokines like IL-1, TNF- $\alpha$, IL-6, IL- 8 and MIP-1 $\alpha$ by inhibiting their expressions. Further IL-4 is associated with increased production of IL-1ra and inhibition of IFN- $\gamma$ leading to a decrease in TNF- $\alpha$ and NO. IL-10, acting through specific cell surface receptors reduces the synthesis of IL-1 and TNF- $\alpha$. IL-10 also inhibits TNF- $\alpha$, IL-1, IL-6, IL-8, IL-12, GMSF, MIP-1 $\alpha$, and MIP-2 $\alpha$ Secretion of proinflammatory cytokines by glial cells is halted on pre-exposure to IL10. IL-10 has been hypothesized to exert the actions by suppressing cytokine receptor expression, inhibiting receptor activation. TGF- $\beta$ impedes the production of IL-2, IFN- $\gamma$ and TNFs. Three mammalian isoforms of TGF- $\beta$ i.e. TGF- $\beta 1$, TGF- $\beta 2$ and TGF- $\beta 3$ are prevalent within the CNS. TGF- $\beta$ is associated with a plethora of activities including microglial activation to inflammatory response, astrocytes, and regulation of COX-2 and APP. Interestingly, elevated levels of TGF- $\beta 1$ and TGF- $\beta 2$ have been observed in CSF and blood of $\mathrm{AD}$ patients $[39,40]$.

\subsection{APP protein}

APP is a transmembrane protein present in the cell membrane of all neurons. Under normal conditions, $\alpha$ secretase and $\gamma$ secretase cleaves APP into three fragments which in turn get digested via proteosomes (nonamyloidogenic pathway). During the initial phases of AD, the amyloidogenic pathway takes over and $\beta$ secretase becomes involved in the process in place of $\alpha$ secretase [41]. $\alpha$ secretase activity is exerted by three members of A disintegrin and metalloprotease (ADAM) family viz. ADAM9, ADAM10 and ADAM17/ TNF- $\alpha$ converting 
enzyme (TACE). The $\beta$-secretase activity has been mainly attributed to the $\beta$-site APP cleaving enzyme. The $\gamma$-secretase complex comprises presenilin (PSEN), nicastrin, anterior pharynx defective-1 (APH-1), and presenilin enhancer-2 (Pen-2). The amyloidogenic pathway predominantly gives rise to fragments like sAPP $\beta$, APP intracellular domain (AICD) and $A \beta$ peptide spanning from 1-40 amino acid residues. These abnormal fragments are not digested resulting in extracellular accumulation of aggregates or plaques of those fragments. These senile plaques are termed $\beta$ amyloids or $A \beta$ lipoproteins. They, in turn, lead to neurotoxicity, apoptosis, oxidative stress and neuroinflammation. $\beta$ amyloids, in addition to generating inflammatory responses, also cause mechanical disruption in synaptic transmission [42].

\subsection{TAU phosphorylation}

TAU protein stabilizes microtubules. Microtubules are very important for the cytoskeletal integrity of a cell. They reside throughout the axon to aid transport proteins move nutrients and neurotransmitters. Microtubules lose their structure in absence of TAU and break apart. When $\beta$ secretase becomes more active than $\alpha$ secretase, a high amount of $\beta$ amyloid is produced. $\beta$ amyloid, in turn, causes hyperpolarisation of TAU protein through excessive phosphorylation of TAU [43]. On hyperpolarisation, TAU protein starts aggregating with each other. Unlike senile plaques, TAU clumps stay inside neuronal cell. As a result, the cytoskeleton starts to fall apart. Under this condition, axonal transport gets hampered. Neurotransmitter transport from soma to synaptic bud becomes affected and neuronal function decreases. Not only neurotransmitters, flow of nutrients inside the longest cell of the body would also suffer and gradually axons and dendrons would start to degenerate. Cluster of such neurons forms neurofibrillary tangles. Cytokines with kinase activity on TAU include cyclin-dependent kinase 5 (CDK5), glycogen synthase kinase-3 $\beta$ (GSK-3 $\beta$ ) and p38 mitogenactivated protein kinases (p38-MAPK) [44]. 


\subsection{Glial cells}

Progress in AD-related research has revealed important roles of glial cells like astrocytes, microglia, NG2 glia, and oligodendrocytes in the pathogenesis of the disease [45]. Astrocytes and microglia participate either by functioning as effector cells to release cytokines by somehow failing to live up to their homeostatic functions. NG2 glia, a novel and distinct class of glial cells in CNS are responsible for myelination and remyelination of axons thus playing a vital role in high-speed nerve impulse transport and cognition [46]. Amyloid peptides and their precursor APP protein act as glial activators. Disruption of the APP gene and its proteolytic products delay and decrease amyloid-dependent microglial activation.

Astrocytes are star-shaped glial cells in CNS involved in energy reserves, regulation of extracellular ions, as well as the clearance, metabolism of neurotransmitters, and modulation of oxidative stress. Neurotransmitter glutamate is released during neuroinflammatory conditions mainly which in the long-term is proved to be toxic to neurons via the excitotoxicity pathway. Astrocytes can take up glutamate and recycle it to neurons after transforming into glutamine, an amino acid [47]. During AD, A $\beta$ peptides decrease uptake of glutamate, thus increasing oxidative stress. Interestingly, alongside the neuroprotective activities of astrocytes through $\mathrm{A} \beta$ clearance and degradation, they could also be a source of $\mathrm{A} \beta$ owing to their overexpression of BACE1 in response to chronic stress [48].

Migration of astrocytes to amyloid plaques is promoted by chemokines CCL2 and CCL3, which are released by activated microglial cells. Mouse astrocytes plated on amyloidrich brain sections from APP transgenic mice have been found to reduce amyloids [49]. Astrocytes respond to CNS insults through a process named reactive astrogliosis, an early pathological feature of $\mathrm{AD}$ and can represent a response to the accumulation of amyloid and/ or to the increasing number of degenerating neurons [50]. Astrocytes can be stimulated by oxidative stress, free saturated fatty acids, pathogens and lipopolysaccharides. Contrary to 
quiescent astrocytes, reactive astrocytes can produce cytokines, such as TNF $\alpha$, IFN $\gamma$ and ILs [51]. IFN- $\beta$, TNF- $\alpha$ and IL-1 $\beta$, induce the generation of $A \beta$ in primary human astrocytes and astrocytoma cells.

Astrogliosis is characterized also by a high level of the astrocyte marker glial fibrillary acidic protein (GFAP). The latter occurs around amyloid deposits both in the brain parenchyma and in the cerebral microvasculature. Senile plaques are associated with GFAPpositive-activated astrocytes. In various neuropathological states, the increased expression of GFAP corresponds to the severity of astroglial activation [52]. Microglial cells and astrocytes express pathogen recognition receptors e.g. toll-like receptors, integrin $\alpha 6 \beta 1, \mathrm{~A} 1, \mathrm{CD} 36$, CD47, CD14 to act as class A scavenger receptors through DAMP [9].

Oligodendrocytes, under the influence of NG2 cells, are responsible for myelin sheath generation around axons. A study concluded that $\mathrm{A} \beta$ peptides induce local translation of myelin basic protein $18.5 \mathrm{kDa}$ isoform in distal cell processes[53]. $\mathrm{A} \beta$ oligomers modulate the expression of myelin basic protein with the help of the integrin $\beta 1$ receptor, Src-family kinase Fyn and $\mathrm{Ca} 2+/ \mathrm{CaMKII}$. The pharmacological inhibition of Fyn kinase can attenuate oligodendrocyte differentiation and survival induced by $\mathrm{A} \beta$. In ex vivo organotypic cerebellar slices, $A \beta$ caused upregulation of myelin basic protein through Fyn kinase and modulated oligodendrocyte population dynamics by inducing cell proliferation and differentiation [53]. Application of $A \beta$ oligomers to cerebellar organotypic slices, enhance remyelination and oligodendrocyte lineage recovery in case of lysolecithin-induced demyelination.

\subsection{Advanced glycation end products}

Advanced glycation end products mediate crosslinking of certain proteins resulting in agerelated decline in cognition and other cellular functions. RAGE, a ligand for both $A \beta$ and S100B is also associated with the activity [54]. In hyperglycaemic patients, unusual glucose 
metabolism and oxidative stress aggravate the activities of advanced glycation end products. This may be correlated with the fact that; excess dietary carbohydrates and deficient cholesterol may lead to the development of AD. Intracellular neurofibrillary tangles and extracellular senile plaques serve as substrates for glycation. Advanced glycation end products induce the production of ROS and cytokines through activation of microglial RAGE leading to engagement of NFKB [55]. It has been clinically observed that low dietary intake of advanced glycation end products is directly related to reduced oxidative stress and inflammation [56,57].

\subsection{Complement system}

At an early stage of $\mathrm{AD}, \mathrm{A} \beta$ peptides activate the complement systems. The complement system works as a part of the immune system to remove unwanted bodies through antibodymediated phagocytosis. In course of doing so, complementary proteins interact with cell surface receptors to promote an inflammatory response in the host system. Complement system attacks and destroys invaders in four steps viz. recognition, opsonization, inflammatory stimulation, and killing. In the human brain, epicenter of complement activity lies within astrocytes. They can synthesize complement proteins like $\mathrm{C} 1-\mathrm{C} 9$, regulatory factors $\mathrm{B}, \mathrm{D}, \mathrm{H}$, I and complement receptors like $\mathrm{C} 1 \mathrm{qR}, \mathrm{C} 3 \mathrm{aR}$ and $\mathrm{C} 5 \mathrm{aR}$ locally to defend through both classical and alternative pathways [36]. Microglia also supports phagocytosis by expressing C1q, $\mathrm{C} 3$ proteins and $\mathrm{C} 1 \mathrm{qR}, \mathrm{CR} 3, \mathrm{C} 5 \mathrm{aR}$ receptors [58]. Apart from neuroglia, neurons also express regulatory factors $\mathrm{H}, \mathrm{S}$ and receptors $\mathrm{C} 1 \mathrm{qR}, \mathrm{C} 3 \mathrm{aR}$ and $\mathrm{C} 5 \mathrm{aR}$. Complement protein $\mathrm{Clq}$ affects the formation of amyloid plaques containing $\beta$-sheet structure [59]. In transgenic $\mathrm{AD}$ mice, inhibition of complement system by $\mathrm{C} 3$ knockout resulted in increased formation of amyloid plaques further supports a neuroprotective role of the complement system [59-61]. 


\section{Macrophage migration inhibitory factors in AD: pathogenic or protective?}

MMIF, also termed as glycosylation inhibiting factor is classified as a proinflammatory cytokine being an important regulator of innate immunity. Expression of MMIF correlates with expression of VEGF in CNS [62]. Interestingly, glucocorticoids stimulate the secretion of MMIF whereas glucocorticoids are known to suppress most of the other cytokines. Thus, MMIF acts against the general anti-inflammatory response of glucocorticoids. There exists a debate on whether endogenous MMIFs support or counter the pathogenesis of AD. Enhanced MMIFs have been reported in mouse models of neurodegenerative disorders $[9,63]$. Again, several studies reported that MMIF knockdown in mutant mice has resulted in acceleration of neurodegenerative disorders [64,65]. MMIFs have also been reported to regulate neuroinflammation and autophagy in the favour of neuroprotection $[63,66,67]$.

MMIF controls the synthesis and release of TNF- $\alpha$, IL-1, and other cytokines. MMIF is also involved in macrophage functions like phagocytosis and tumoricidal activities. Brain insulin-resistant state arises due to prolonged exposure of cortical neurons to high concentrations of insulin. MMIF contributes to this insulin-resistant state through inhibition of phosphorylation of Akt [68]. In some cases, a structural homologue of MMIF, Ddopachrome tautomerase (MIF-2) exhibits synergistic activities in combination with MMIF [69]. MMIF and $A \beta_{1-42}$ fragments of senile plaques display similar neurotoxicity patterns. In another in vitro cell study, it was observed that ISO-1, an MMIF inhibitor successfully retracted neurotoxicity mediated by $\mathrm{A} \beta$ peptides further strengthening the correlation between $\mathrm{A} \beta$ and MMIF [70]. The study also reported enhanced MMIF levels in CSF of AD patients [70]. In another experiment, MMIF knockout successfully limited TAU hyperphosphorylation in the mouse model [71]. In silico studies suggest that MMIF may be involved in neuronal apoptosis during AD [72]. Interestingly, Popp et al (2009) did not find any difference in MMIF levels of AD patients with mild, moderate and severe dementia. In 
short, we can say that imbalance between oxidized and reduced isoforms of MMIF is the key to regulate the switch to either diseased or normal state [73].

\section{Choroid plexus growth factors and AD}

Growth-promoting properties of APP, along with other growth factors, play vital roles in the development of AD. Choroid plexus supports neuronal function by secreting CSF. VEGF and FGF can be found in epithelial cells of the choroid plexus. Choroid plexus is rich in various proteins and their receptors. Proteins include FGF-2, TGF- $\alpha$ and TGF- $\beta$ along with mRNA expressions for TGF- $\beta$, IGF-II, FGF-2 receptors and NGF receptors. Choroid plexus also contains receptor binding sites for FGF-7, keratinocyte growth factor, insulin-like growth factor (IGF) 1 and IGF-2. Blood-CSF barrier made up of epithelial cells and tight junctions at choroid plexus allows selective passage of materials into the brain. FGF-2 has been reported to increase in brain parenchyma of AD patients. Infusion of FGF-2 in rat model has resulted in hydrocephalus ex vacuo which is a clinical feature of AD [74]. Improper CSF circulation and impaired clearance of CSF may give rise to dementia and neurodegeneration due to lack of nutrition to CNS cells and toxic accumulations within CSF.

\subsection{Vascular endothelial growth factors}

Vascular endothelial growth factors (VEGF) and their receptors have been reported to localize at the area with lesions and AD-related developments. Different isoforms of VEGF act as a proinflammatory-cytokine by increasing endothelial cell permeability, inducing expression of endothelial cell adhesion molecules and acting as monocyte chemoattractants [75]. VEGF is involved in the regulation of GLUT1 and tissue thromboplastin, which in turn regulate vascular pathologies of AD. GLUT1, present in BBB mediates glucose transport into the brain and reduced expression of GLUT1 is relatable with aggravated AD conditions. Tissue thromboplastin and derived factors play a proinflammatory role leading to vascular 
dementia [76]. AD patients tend to present with enhanced VEGF activity within reactive astrocytes [77]. Rats induced with astrogliosis displayed increased astrocytic and perivascular reactivity within the cerebral cortex [78].

\subsection{Fibroblast growth factors}

FGFs are circulatory proteins playing important roles to activate cell surface receptors. Around 23 FGF subtypes have been known to exert distinct functions till date [79]. Acidic FGF-1 and basic FGF-2, among eight other FGF family proteins, act through four families of FGF receptors. FGF-11 to14 do not act through FGF receptors.

FGF-1 and FGF-2 are more potent angiogenic factors than VEGF [80]. Within CNS, FGFs play the important roles in proper proliferation and differentiation of neuronal stem cells including neurogenesis and axonal growth. FGFs also support the self-renewal of radial glial cells. FGF-8 is a vital player for the proper functioning of the cerebral cortex. Increased levels of FGF-2 have reportedly been associated with AD brain leading to enlargement of ventricles [81]. FGFs regulate not only neuronal stem cells but also adult neurogenesis. Maintenance and survival of neurons throughout their lifetime depend greatly on FGF-2. Synaptic plasticity is, to some extent controlled by FGF-1 and FGF-2. Thus, proper conduction of nerve impulses through axons and synapses for proper cognition is dependent upon FGFs. Belluardo et al (2004) have demonstrated that upregulation of FGF-2 can successfully prevent neuronal loss in cortical and hippocampal regions of the brain [82]. In the rat models, FGF-21 has been found to ameliorate $\mathrm{A} \beta$ peptide-mediated neurodegeneration [83]. The effects were achieved via PP2A/ MAPK/ HIF-1 $\alpha$ pathways interfering with TAU pathologies and minimizing oxidative stress [83]. 


\section{Neurotrophic factors}

Neurotrophic growth factors, produced by neural stem cells are involved in the differentiation of cells and cell survival. Neurotrophic growth factors consist of NGFs, glial cell line-derived neurotrophic factor (GDNF), neurokines, and non-neuronal growth factors. NGF is probably the most discussed neurotrophic growth factor and neuropeptide primarily involved in the regulation of growth, maintenance, proliferation, and survival of certain target neurons. NGF was the first neurotrophin to be discovered followed by brain-derived neurotrophic factors, neurotrophin-3, neurotrophin 4/5, and neurotrophin-6 [84]. Neurotrophins bind to cognate Trk receptors and $\mathrm{p} 75 \mathrm{NTR}$ receptors. The low-affinity neurotrophin receptor $\mathrm{p} 75$ can bind with all neurotrophin family members. Neurokines and cytokines related to interleukin-6 (IL6) bind to cell surface receptor complexes, which share a common structural organization. The four ligands interchangeably employ two distinct receptor subunits, leukemia inhibitory factor receptor b (LIFR b) and gp130; some employ a ligand-specific $\alpha$ subunit [85].

NGF exhibits protective action over cholinergic neurodegeneration. NGF can influence APP processing towards the non-amyloidogenic pathway via protein kinase C coupled M1 and M3 receptors. Interestingly, NGFs are upregulated in AD patients' brain and CSF while NGF receptor TrKA is downregulated [36]. AD patients exhibit a higher phosphorylated TAU to $\mathrm{A} \beta$ peptide ratio compared to healthy individuals indicating towards the accumulation of NGF during the development of the disease. Brain-derived neurotrophic factors alone and in chimeric combination with NGF has been found to protect cholinergic neurons in prosencephalon [86]. AD brains have been diagnosed with decreased levels of mRNAs for brain-derived neurotrophic factors but normal levels of mRNAs for NGF and neurotrophin-3 [87]. In the AD brain, astrogliosis may contribute to increased NGF and reduced TrKA in the cortex and nucleus basalis. Vinculin-dependent adhesions are central to the functioning of NGF to promote axonal outgrowth. Vinculin-dependent coupling regulates 
the level of myosin needed for NGF stimulation. The role of NGF as a growth factor amongst a bouquet of proteins is paramount in cognitive processes that may be involved in the survival and phosphorylation of fibrils in axons, that are involved in $\mathrm{AD}$ and other chronic diseases closely related to AD [88].

\section{Haematopoietic growth factors}

Apart from controlling hematopoiesis in blood progenitor cells, hematopoietic growth factors like IL-3, GCSF, granulocyte macrophage colony-stimulating factor (GMCSF), MCSF, and erythropoietin play vital roles in the functional activation of all mature cells. In the biological and pathological role of the immune system, the immune system achieves its role by cells that encapsulate it as a whole. Such cells originate from hematopoietic stem cells in the bone marrow by a blood-forming process of hematopoiesis that give rises to myeloid progenitor cells and lymphoid progenitor cells [89]. Myeloid progenitor cells constitute megakaryocytes, erythrocytes, mast cells, and myeloblast. The myeloblast cells antithesize into immune cells, namely, basophil, neutrophil, eosinophil, and monocytes. Of the subset of the myoblast cells are the monocytes that later develop into macrophages, which play an initiating part in immune system responses that counter foreign material, pathogens, and compromised cells in the CNS.

Hematopoietic growth factors are important contributors to brain marrow for neuropoiesis. They can prevent neuronal death to some extent. Jin et al (2004) have pointed out enhanced neurogenesis during $\mathrm{AD}$ [90], though many pose doubts on the marker doublecortin $[91,92]$. In the mouse models, GCSF has been observed to restore cognition by restoring acetylcholine levels [93]. Stem cell factors, in combination with receptor c-kit stimulate neurogenesis [94]. Lower level of stem cell factor in blood and CSF indicate faster cognitive decline during $\mathrm{AD}$ [95]. Increased levels of angiopoietins 1 and 2 indicate cognitive a decline in $\mathrm{AD}$. In the mouse models, angiopoietin 1 accelerates $\mathrm{AD}$ via FOXA2/PEN2/APP 
pathway [96]. Increased neurogenesis, anti-apoptotic influences, and mobilization of microglia contribute to brain repair involving hematopoietic growth factors.

\section{Cytokines in the pathophysiology of AD: at a glance}

Cytokines that mediate cell functioning, cell signaling behaviours, and neuro-immune activity are classified by the actions that they solicit. In the immune response, such cytokines are proinflammatory cytokines, anti-inflammatory cytokines and cytokines that inhibit virus replication. They can prevent neuronal death, macrophage-activating cytokines, B-cell activating cytokines, T-cell activating cytokines and mast-cell activating cytokines. In $\mathrm{AD}$, certain cytokines are involved in the immune responses that precede and importune the actions of other cytokines in the innate neuroimmune inflammatory reactions that are observed in $\mathrm{AD}$ consequent of aberrant pathologies in the brain and concomitant to $\mathrm{CNS}$ insults such as, neurotoxicity, accumulation of $\mathrm{A} \beta$ senile plaque and TAU pathologies (Table 2). IL-1 $\alpha$ containing plasmids were analysed in IL-1 cDNA clones by the hybrid selection of biologically active mRNA that resulted in abundant IL-1 in lipopolysaccharide-stimulated macrophages [97]. Of the classes of cytokines that are implicated in $\mathrm{AD}$, specialized groups of cytokines are differentiated by the availability of their receptors expressed on the cell surface of implicated cell types and the condition of the genes that regulate these receptors.

Inflammation, inflammation-mediated expression of iNOS, and iNOS mediated release of NO play instrumental roles to degenerate neurons during AD [98]. In neurons, cytokines are believed to play a major role in routine neurological activities of the CNS in the transfer and reception of chemical cues that confer instructions on cell actions and reactions. Chemotactic cytokines that function as chemoattractant cytokines such as IL-8, IP-10) / CXCL 10 may experience N-terminal proteolytic alteration after being secreted. In AD where neurofibrillary tangles have been observed to be further propagated through the toxicity presented by $\mathrm{A} \beta$ plaque accumulation and loss of cholinergic neurons in rat basal forebrain 
primary septal culture [99]. A $\beta$ prevented microtubule binding in primary cultures of fetal rat hippocampal neurons and human cortical neurons and induced hyperphosphorylated TAU at Ser-202 and Ser-396 isoforms accumulated in the somatodendritic compartment of A $\beta$ treated neurons [100].

The constituents of axonal projections in the mammalian brain are, neurofilaments that form side projections of carboxy-terminals from the core filament believed to be heavily phosphorylated, and TAU-embellished microtubules that are known to be differentially phosphorylated. The $\alpha$ and $\beta$ globulin subunits that constitute axonal microtubules are formed by the process of nucleation which is energy-consuming. An energy-expensive neuro-process would require optimal active mitochondria to properly conduct impulse. Hyperphosphorylation of TAU has been credited to play an acting role in the impairment of axonal support functioning to optimize communications amongst associated organelles interneuronally. NGF is a key growth factor in functional axonal growth and proliferation that is evident as important through other chronic and neurodegenerative diseases that adversely affect neuroimmune processes [101], therefore CNS coordination [102]. Similarly, to oxidative stress observed in AD brains that may lead to hyperphosphorylation of TAU. Where the absence of superoxide dismutase (SOD) was observed to increase oxidation damage from ROS; an escalation of Ser-36 phospho-TAU was revealed in treatments of SOD null mice; untreated mice did not survive past one week, SOD deficiency was therefore deleterious [103]. Notably, an increase in myosin IIB (MIIB) was also found to mirror the increasing depletion of SOD activity in chronically diabetic rats [104].

Symptomatic connections and similarities that exist between $\mathrm{AD}$ and other chronic diseases such as hypoxia and Parkinson's disease may underlie related mechanisms of similar pathways and molecular neurodegenerative mechanisms leading to those symptoms that may also be regarded as risk factors leading to encephalitis-like symptoms in early diagnosis of 
AD or presymptomatic MCI. Such symptoms include depression, depleted cognitive function, hallucinations, reduced glucose metabolism, sleep pattern changes, appetite changes, optophysiological decline, vision loss or blindness etc.

The growth factor VEGF was responsible for the permeability of cytokines and may serve as a permeability factor involve in the pathogenic scenarios. VEGF may consist of an AD-depression mediated mechanism of cognitive decline while neuroinflammation could possibly contribute to depression. Toll-like-receptors mediate the signalling of transcription factors that produced proinflammatory cytokines in microglial response in isolated and purified mouse brain tissue where TREM2 knockdown expressed an upregulation of TNF- $\alpha$ [105]. SORL1 increases the trafficking of APP to the cells undergoing the amyloidogenic pathway, thus contributing to the development of $\mathrm{AD}$.

\subsection{Cytokines and BBB}

There exists a definite correlation between brain cytokine levels and neuropsychiatric disorders. Right at this point, selectivity and integrity of BBB to cytokines become important. Cytokines are pleiotropic, hence their release, unlike hormones has more complicated effects on the regulation of neurotransmission. They can cross BBB, activate free calcium, and by disrupting the compartmental model of brain calcium homeostasis, compromise the integrity of BBB [12]. Many cytokines can pass through BBB directly [106]. Glial cell-derived neurotrophic factors bypass the BBB by simple diffusion through circumventricular organs. Passage of IL-1 $\alpha$, IL-6, and TNF- $\alpha$ involves saturable influx transport through retrograde axonal transport system $[12,107]$. TNF- $\alpha$, a downstream cytokine of chemokine IP10 decreases tight junction proteins leading to the destruction of endothelial tight junctions of BBB to affect its permeability $[108,109]$. Inhibition of mTOR hyperactivity has been reported to protect the integrity of $\mathrm{BBB}$ in $\mathrm{AD}[110]$. BBB dysfunction brings about early aging in the brain paving the way for $\mathrm{AD}$ and other neurodegenerative disorders. 


\section{Potential strategies involving cytokines for management of AD}

$\mathrm{AD}$ affects millions of individuals worldwide among the aging population, yet no therapeutic intervention is available to stop and eliminate this disorder. Neuropathological hallmarks of $\mathrm{AD}$ are extracellular deposits of $\mathrm{A} \beta$ peptides assembled in plaques, intraneuronal accumulation of hyperphosphorylated TAU protein forming neurofibrillary tangles and chronic neuroinflammation. No absolute cure for AD is available till date [111].

Cholinesterase inhibitors and NMDA antagonists display moderate relief in the case of AD. Donepezil, an inhibitor of acetylcholinesterase improved cognitive conditions in AD and increased brain-derived neurotrophic factors [112]. Pharmacotherapy against A $\beta$ and TAU have yielded limited success only. Treatment with $\beta$-sheet breaker peptides results in reduced brain inflammation by disrupting amyloids [113]. RAGE/NF- $\kappa \mathrm{B}$ axis could be a potential therapeutic target in AD [114]. Some dietary nutraceuticals display inhibitory effects on the formation of advanced glycation end products [115]. Resveratrol has been found to modulate levels of $\beta$-amyloids and certain inflammatory markers in AD patients [116]. Luteokin can play a prophylactic role against AD [117]. Moderate activation of microglia is thought to have beneficial effects in removing neurotoxins, cellular debris, or dying cells, and also in promoting neuronal survival. Since MMIF is augmented in AD, measuring blood and CSF levels of MMIF may represent a diagnostic biomarker useful both for diagnosis and therapeutic monitoring of the disease [118]. Moderate activation of microglia by acute neuroinflammation is thought to have beneficial effects in removing neurotoxins, cellular debris or dying cells and also in promoting neuronal survival [119]. IL-1 ra, a glycosylated protein antagonizes the cell activating action of IL-1. TNF- $\alpha$ has been reported to possess neuroprotective effects [120]. TGF- $\beta$ is capable of converting an active site of inflammation into one dominated by reparations [121]. Kitazawa et al (2011) described that blocking IL-1 signalling in 3xtg AD mice with an IL-1 receptor blocking 
antibody was beneficial, since it leads to a decrease in certain $\mathrm{A} \beta$ fibrillar forms and plaques [122].

It has been suggested that a blockade of the ongoing inflammatory processes may delay the progression of AD [123]. Studies suggest lesser incidents of arthritis patients receiving NSAIDs regularly developing AD [124,125]. The fact that COX-2 mRNA is upregulated in $\mathrm{AD}$ brain, further supports this claim. Receptors for hematopoietic growth factors expressed on neurons provide novel targets for drug discovery in the search for agents that can reverse the progression of $\mathrm{AD}$.

It is interesting to observe that peripheral phagocytes can effectively clear plaques and therapeutic strategies aiming at favoring the recruitment of these cells into the CNS are actively being pursued [9]. In the mouse models, the brain-derived neurotrophic factors have improved AD conditions by delaying synapse loss, improving cell signalling and improving cognition and spatial learning [126]. GCSF and analogues have proven neuroprotective activity which may possibly be used therapeutically. In vivo intra-peritoneal VEGF administration reduced cognitive impairment in the mice model of AD [127]. As discussed earlier, NGFs are potential candidates for significant improvement of cognitive functions. Biogenetic exosome-mediated activation of microglia and deregulation of microRNA can be useful to fight to neuroinflammation [128]. Erythropoietin, together with NFאB can prevent neuronal injury triggered by $\beta$-amyloid toxicity [129]. Inhibitors of TNF- $\alpha$ have exhibited potential promise to slow down the progress of AD-associated cognitive decline [130]. Experimentally, improvements have been observed in patients by delivering mature NGFs into the $\mathrm{AD}$ brain [88]. ApoE4 centric treatment approaches are gaining interest in recent times since ApoE4 is involved in more than 50\% of AD cases [131]. M2 microglia are generally engaged in the restoration of homeostatic balance after an inflammatory insult by releasing anti-inflammatory factors. Thus, the therapeutic promise is there to prevent and 
treat neuroinflammation with protective functions of microglia [132-134]. Another potential strategy might be to inhibit $\mathrm{BACE} 1$ to reduce the production of $\mathrm{A} \beta$, however, clinical success is yet to be achieved [135]. Recently, multitarget-directed ligand-based treatment strategies have started to evolve centering on inhibition of glycogen synthase kinase $3 \beta$, a crucial enzyme for TAU hyperphosphorylation, and some other CNS specific signalling pathways [44]. Nowadays, in the war against AD and associated disorders, researchers are focussing more on regulating neurotransmitters, lipid metabolism, autophagy, circadian rhythm, gene therapy etc. [136].

\section{Conclusion}

In this review, ample evidence collected reflects some of the roles of cytokines and growth factors in the pathogenesis of $\mathrm{AD}$ and pathologically related in $\mathrm{AD}$-like neurodegenerative conditions that help understand the propensities and action of cytokines and factors regulating their effects on neuron upon apoptotic decline. Altogether, evidence evinced in previous research on the rather novel concentration on the topic of cytokines in neuroimmune system responses and their role in inflammation possibly preceding neurotoxicity and intra-thecal generation of immune molecules and cytokine-producing cells show that cytokines mediate and even activate innate neuroimmune agents. Cytokines regulate levels of proinflammatory and anti-inflammatory populations to maintain CNS machinery homeostasis [137]. Proinflammatory cytokines induce inflammation in $\mathrm{AD}$ and $\mathrm{AD}$-like pathogenesis in response to the apoptotic scenarios where some growth factors implicated are involved in the expression of cytokinetic reactions to activate microglia that cause inflammation in AD. Cytokines and growth factors such as NGF, VEGF, TNF- $\alpha$, IL-1 additionally impact intricate 
molecular processes necessary for balance and homeostasis in cognitive mechanisms. To conclude, there exists ample scope of improvement regarding clinically useful strategies to mitigate $\mathrm{AD}$.

Author Contributions: GO, SD, VDF and RK contributed to the conceptualization and designing the manuscript. VC, VKK, AC, UA, JV, PG, HPRP, KDG, PHR edited and corrected the manuscript. The final correction and editing were done by GO, SD, VDF, and RK.

Funding: V.D.F provided APC for publishing this manuscript and all the authors acknowledged the same.

Institutional Review Board Statement: Not applicable.

Informed Consent Statement: Not applicable.

Acknowledgments: The authors are thankful to the Council of Scientific and Industrial Research, New Delhi, India, for awarding research project (grant number 02(0275)/16/EMRII) to Saikat Dewanjee. Authors sincerely acknowledge Jadavpur University, India, CSIRIndian Institute of Chemical Technology, Hyderabad, India, for providing necessary facilities, and DBT-India for providing Ramalingaswami Re-entry Fellowship to Ramesh Kandimalla (RK) for the period of 2018-2023 (No. BT/RLF/Re-entry/22/2016 and SAN.No. 102/IFD/SAN/1117/2018-19).

Conflicts of Interest: The authors declare no conflict of interest.

\section{References}

1. Suresh, J.; Khor, I.W.; Kaur, P.; Heng, H.L.; Torta, F.; Dawe, G.S.; Tai, E.S.; Tolwinski, N.S. Shared signaling pathways in Alzheimer's and metabolic disease may point to new treatment approaches. FEBS $J$ 2021, 288, 3855-3873, doi:10.1111/febs. 15540 . 
2. Finkelman, F.D.; Holmes, J.; Katona, I.M.; Urban, J.F., Jr.; Beckmann, M.P.; Park, L.S.; Schooley, K.A.; Coffman, R.L.; Mosmann, T.R.; Paul, W.E. Lymphokine control of in vivo immunoglobulin isotype selection. Annu Rev Immunol 1990, 8, 303 333, doi:10.1146/annurev.iy.08.040190.001511.

3. Alzheimer, A.; Forstl, H.; Levy, R. On certain peculiar diseases of old age. Hist Psychiatry 1991, 2, 71-101, doi:10.1177/0957154X9100200505.

4. Kumar, A.; Singh, A.; Ekavali. A review on Alzheimer's disease pathophysiology and its management: an update. Pharmacol Rep 2015, 67, 195-203, doi:10.1016/j.pharep.2014.09.004.

5. Sattler, S. The Role of the Immune System Beyond the Fight Against Infection. Adv Exp Med Biol 2017, 1003, 3-14, doi:10.1007/978-3-319-57613-8_1.

6. Ohm, D.T.; Fought, A.J.; Martersteck, A.; Coventry, C.; Sridhar, J.; Gefen, T.; Weintraub, S.; Bigio, E.; Mesulam, M.M.; Rogalski, E.; et al. Accumulation of neurofibrillary tangles and activated microglia is associated with lower neuron densities in the aphasic variant of Alzheimer's disease. Brain Pathol 2021, 31, 189204, doi:10.1111/bpa.12902.

7. Allen, H.B.A., R. M.; Cusack, C. A.: Joshi, S. G. Alzheimer's Disease: Intracellular Beta Amyloid Completes the Irreversible Pathway from Spirochetes to Biofilms to Beta Amyloid to Hyperphosphorylated Tau Protein. J Neuroinfect Dis 2018, 9, doi:10.4172/2314-7326.1000276.

8. Heppner, F.L.; Ransohoff, R.M.; Becher, B. Immune attack: the role of inflammation in Alzheimer disease. Nat Rev Neurosci 2015, 16, 358-372, doi:10.1038/nrn3880.

9. Petralia, M.C.; Mazzon, E.; Fagone, P.; Basile, M.S.; Lenzo, V.; Quattropani, M.C.; Di Nuovo, S.; Bendtzen, K.; Nicoletti, F. The cytokine network in the pathogenesis of major depressive disorder. Close to translation? Autoimmun Rev 2020, 19, 102504, doi:10.1016/j.autrev.2020.102504.

10. Biber, K.; Neumann, H.; Inoue, K.; Boddeke, H.W. Neuronal 'On' and 'Off' signals control microglia. Trends Neurosci 2007, 30, 596-602, doi:10.1016/j.tins.2007.08.007. 
11. Sikora, E.; Bielak-Zmijewska, A.; Dudkowska, M.; Krzystyniak, A.; Mosieniak, G.; Wesierska, M.; Wlodarczyk, J. Cellular Senescence in Brain Aging. Front Aging Neurosci 2021, 13, 646924, doi:10.3389/fnagi.2021.646924.

12. Yarlagadda, A.; Alfson, E.; Clayton, A.H. The blood brain barrier and the role of cytokines in neuropsychiatry. Psychiatry (Edgmont) 2009, 6, 18-22.

13. Bahniwal, M.; Little, J.P.; Klegeris, A. High Glucose Enhances Neurotoxicity and Inflammatory Cytokine Secretion by Stimulated Human Astrocytes. Curr Alzheimer Res 2017, 14, 731-741, doi:10.2174/1567205014666170117104053.

14. Saha, R.N.; Pahan, K. Signals for the induction of nitric oxide synthase in astrocytes. Neurochem Int 2006, 49, 154-163, doi:10.1016/j.neuint.2006.04.007.

15. Griffin, W.S.; Liu, L.; Li, Y.; Mrak, R.E.; Barger, S.W. Interleukin-1 mediates Alzheimer and Lewy body pathologies. $J$ Neuroinflammation 2006, 3, 5, doi:10.1186/1742-2094-3-5.

16. Tachida, Y.; Nakagawa, K.; Saito, T.; Saido, T.C.; Honda, T.; Saito, Y.; Murayama, S.; Endo, T.; Sakaguchi, G.; Kato, A.; et al. Interleukin-1 beta up-regulates TACE to enhance alpha-cleavage of APP in neurons: resulting decrease in Abeta production. $J$ Neurochem 2008, 104, 1387-1393, doi:10.1111/j.1471-4159.2007.05127.x.

17. Rivera-Escalera, F.; Pinney, J.J.; Owlett, L.; Ahmed, H.; Thakar, J.; Olschowka, J.A.; Elliott, M.R.; O'Banion, M.K. IL-1beta-driven amyloid plaque clearance is associated with an expansion of transcriptionally reprogrammed microglia. J Neuroinflammation 2019, 16, 261, doi:10.1186/s12974-019-1645-7.

18. Fang, F.; Lue, L.F.; Yan, S.; Xu, H.; Luddy, J.S.; Chen, D.; Walker, D.G.; Stern, D.M.; Yan, S.; Schmidt, A.M.; et al. RAGE-dependent signaling in microglia contributes to neuroinflammation, Abeta accumulation, and impaired learning/memory in a mouse model of Alzheimer's disease. FASEB J 2010, 24, 1043 1055, doi:10.1096/fj.09-139634.

19. Tolar, M.; Abushakra, S.; Sabbagh, M. The path forward in Alzheimer's disease therapeutics: Reevaluating the amyloid cascade hypothesis. Alzheimers Dement 2020, 16, 1553-1560, doi:10.1016/j.jalz.2019.09.075. 
20. Arnsten, A.F.T.; Datta, D.; Tredici, K.D.; Braak, H. Hypothesis: Tau pathology is an initiating factor in sporadic Alzheimer's disease. Alzheimers Dement 2021, 17, 115 124, doi:10.1002/alz.12192.

21. Hampel, H.; Mesulam, M.M.; Cuello, A.C.; Khachaturian, A.S.; Vergallo, A.; Farlow, M.R.; Snyder, P.J.; Giacobini, E.; Khachaturian, Z.S. Revisiting the Cholinergic Hypothesis in Alzheimer's Disease: Emerging Evidence from Translational and Clinical Research. J Prev Alzheimers Dis 2019, 6, 2-15, doi:10.14283/jpad.2018.43.

22. Olloquequi, J.; Cornejo-Cordova, E.; Verdaguer, E.; Soriano, F.X.; Binvignat, O.; Auladell, C.; Camins, A. Excitotoxicity in the pathogenesis of neurological and psychiatric disorders: Therapeutic implications. J Psychopharmacol 2018, 32, 265 275, doi:10.1177/0269881118754680.

23. Kinney, J.W.; Bemiller, S.M.; Murtishaw, A.S.; Leisgang, A.M.; Salazar, A.M.; Lamb, B.T. Inflammation as a central mechanism in Alzheimer's disease. Alzheimers Dement (N Y) 2018, 4, 575-590, doi:10.1016/j.trci.2018.06.014.

24. Chen, S.; Yang, J.; Wei, Y.; Wei, X. Epigenetic regulation of macrophages: from homeostasis maintenance to host defense. Cell Mol Immunol 2020, 17, 36-49, doi:10.1038/s41423-019-0315-0.

25. Ramesh, G.; MacLean, A.G.; Philipp, M.T. Cytokines and chemokines at the crossroads of neuroinflammation, neurodegeneration, and neuropathic pain. Mediators Inflamm 2013, 2013, 480739, doi:10.1155/2013/480739.

26. Ennerfelt, H.E.; Lukens, J.R. The role of innate immunity in Alzheimer's disease. Immunol Rev 2020, 297, 225-246, doi:10.1111/imr.12896.

27. Taipa, R.; das Neves, S.P.; Sousa, A.L.; Fernandes, J.; Pinto, C.; Correia, A.P.; Santos, E.; Pinto, P.S.; Carneiro, P.; Costa, P.; et al. Proinflammatory and antiinflammatory cytokines in the CSF of patients with Alzheimer's disease and their correlation with cognitive decline. Neurobiol Aging 2019, 76, 125-132, doi:10.1016/j.neurobiolaging.2018.12.019.

28. Alasmari, F.; Alshammari, M.A.; Alasmari, A.F.; Alanazi, W.A.; Alhazzani, K. Neuroinflammatory Cytokines Induce Amyloid Beta Neurotoxicity through Modulating Amyloid Precursor Protein Levels/Metabolism. Biomed Res Int 2018, 2018, 3087475, doi:10.1155/2018/3087475. 
29. Popp, J.; Oikonomidi, A.; Tautvydaite, D.; Dayon, L.; Bacher, M.; Migliavacca, E.; Henry, H.; Kirkland, R.; Severin, I.; Wojcik, J.; et al. Markers of neuroinflammation associated with Alzheimer's disease pathology in older adults. Brain Behav Immun 2017, 62, 203-211, doi:10.1016/j.bbi.2017.01.020.

30. Bansal, Y.; Singh, R.; Parhar, I.; Kuhad, A.; Soga, T. Quinolinic Acid and Nuclear Factor Erythroid 2-Related Factor 2 in Depression: Role in Neuroprogression. Front Pharmacol 2019, 10, 452, doi:10.3389/fphar.2019.00452.

31. Khemka, V.K.; Ganguly, A.; Bagchi, D.; Ghosh, A.; Bir, A.; Biswas, A.; Chattopadhyay, S.; Chakrabarti, S. Raised serum proinflammatory cytokines in Alzheimer's disease with depression. Aging Dis 2014, 5, 170-176, doi:10.14336/AD.2014.0500170.

32. Kaur, D.; Sharma, V.; Deshmukh, R. Activation of microglia and astrocytes: a roadway to neuroinflammation and Alzheimer's disease. Inflammopharmacology 2019, 27, 663-677, doi:10.1007/s10787-019-00580-x.

33. Patel, N.S.; Paris, D.; Mathura, V.; Quadros, A.N.; Crawford, F.C.; Mullan, M.J. Inflammatory cytokine levels correlate with amyloid load in transgenic mouse models of Alzheimer's disease. J Neuroinflammation 2005, 2, 9, doi:10.1186/1742-2094-2-9.

34. Winter, C.D.; Iannotti, F.; Pringle, A.K.; Trikkas, C.; Clough, G.F.; Church, M.K. A microdialysis method for the recovery of IL-1beta, IL-6 and nerve growth factor from human brain in vivo. $J$ Neurosci Methods 2002, 119, 45-50, doi:10.1016/s01650270(02)00153-x.

35. Chong, Y. Effect of a carboxy-terminal fragment of the Alzheimer's amyloid precursor protein on expression of proinflammatory cytokines in rat glial cells. Life Sci 1997, 61, 2323-2333, doi:10.1016/s0024-3205(97)00936-3.

36. Rubio-Perez, J.M.; Morillas-Ruiz, J.M. A review: inflammatory process in Alzheimer's disease, role of cytokines. ScientificWorldJournal 2012, 2012, 756357, doi:10.1100/2012/756357.

37. Agbo, D.B.; Neff, F.; Seitz, F.; Binder, C.; Oertel, W.H.; Bacher, M.; Dodel, R. Immunization as treatment for Parkinson's disease. J Neural Transm Suppl 2009, 311315, doi:10.1007/978-3-211-92660-4_26. 
38. Liu, J.; Zhao, M.L.; Brosnan, C.F.; Lee, S.C. Expression of type II nitric oxide synthase in primary human astrocytes and microglia: role of IL-1beta and IL-1 receptor antagonist. J Immunol 1996, 157, 3569-3576.

39. Wyss-Coray, T.; Lin, C.; von Euw, D.; Masliah, E.; Mucke, L.; Lacombe, P. Alzheimer's disease-like cerebrovascular pathology in transforming growth factorbeta 1 transgenic mice and functional metabolic correlates. Ann N Y Acad Sci 2000, 903, 317-323, doi:10.1111/j.1749-6632.2000.tb06382.x.

40. Chao, C.C.; Hu, S.; Frey, W.H., 2nd; Ala, T.A.; Tourtellotte, W.W.; Peterson, P.K. Transforming growth factor beta in Alzheimer's disease. Clin Diagn Lab Immunol 1994, 1, 109-110, doi:10.1128/cdli.1.1.109-110.1994.

41. Schaduangrat, N.; Prachayasittikul, V.; Choomwattana, S.; Wongchitrat, P.; Phopin, K.; Suwanjang, W.; Malik, A.A.; Vincent, B.; Nantasenamat, C. Multidisciplinary approaches for targeting the secretase protein family as a therapeutic route for Alzheimer's disease. Med Res Rev 2019, 39, 1730-1778, doi:10.1002/med.21563.

42. Mroczko, B.; Groblewska, M.; Litman-Zawadzka, A.; Kornhuber, J.; Lewczuk, P. Amyloid beta oligomers (AbetaOs) in Alzheimer's disease. J Neural Transm (Vienna) 2018, 125, 177-191, doi:10.1007/s00702-017-1820-x.

43. Alonso, A.D.; Cohen, L.S.; Corbo, C.; Morozova, V.; ElIdrissi, A.; Phillips, G.; Kleiman, F.E. Hyperphosphorylation of Tau Associates With Changes in Its Function Beyond Microtubule Stability. Front Cell Neurosci 2018, 12, 338, doi:10.3389/fncel.2018.00338.

44. De Simone, A.; Tumiatti, V.; Andrisano, V.; Milelli, A. Glycogen Synthase Kinase 3beta: A New Gold Rush in Anti-Alzheimer's Disease Multitarget Drug Discovery? $J$ Med Chem 2021, 64, 26-41, doi:10.1021/acs.jmedchem.0c00931.

45. Dzamba, D.; Harantova, L.; Butenko, O.; Anderova, M. Glial Cells - The Key Elements of Alzheimer s Disease. Curr Alzheimer Res 2016, 13, 894-911, doi:10.2174/1567205013666160129095924.

46. Baaklini, C.S.; Rawji, K.S.; Duncan, G.J.; Ho, M.F.S.; Plemel, J.R. Central Nervous System Remyelination: Roles of Glia and Innate Immune Cells. Front Mol Neurosci 2019, 12, 225, doi:10.3389/fnmol.2019.00225. 
47. Vesce, S.; Rossi, D.; Brambilla, L.; Volterra, A. Glutamate release from astrocytes in physiological conditions and in neurodegenerative disorders characterized by neuroinflammation. Int Rev Neurobiol 2007, 82, 57-71, doi:10.1016/S00747742(07)82003-4.

48. Rossner, S.; Lange-Dohna, C.; Zeitschel, U.; Perez-Polo, J.R. Alzheimer's disease beta-secretase BACE1 is not a neuron-specific enzyme. J Neurochem 2005, 92, 226234, doi:10.1111/j.1471-4159.2004.02857.x.

49. Wyss-Coray, T.; Loike, J.D.; Brionne, T.C.; Lu, E.; Anankov, R.; Yan, F.; Silverstein, S.C.; Husemann, J. Adult mouse astrocytes degrade amyloid-beta in vitro and in situ. Nat Med 2003, 9, 453-457, doi:10.1038/nm838.

50. Liu, C.Y.; Yang, Y.; Ju, W.N.; Wang, X.; Zhang, H.L. Emerging Roles of Astrocytes in Neuro-Vascular Unit and the Tripartite Synapse With Emphasis on Reactive Gliosis in the Context of Alzheimer's Disease. Front Cell Neurosci 2018, 12, 193, doi:10.3389/fncel.2018.00193.

51. Liu, L.; Martin, R.; Chan, C. Palmitate-activated astrocytes via serine palmitoyltransferase increase BACE1 in primary neurons by sphingomyelinases. Neurobiol Aging 2013, 34, 540-550, doi:10.1016/j.neurobiolaging.2012.05.017.

52. Chen, Y.; Qin, C.; Huang, J.; Tang, X.; Liu, C.; Huang, K.; Xu, J.; Guo, G.; Tong, A.; Zhou, L. The role of astrocytes in oxidative stress of central nervous system: A mixed blessing. Cell Prolif 2020, 53, e12781, doi:10.1111/cpr.12781.

53. Quintela-Lopez, T.; Ortiz-Sanz, C.; Serrano-Regal, M.P.; Gaminde-Blasco, A.; Valero, J.; Baleriola, J.; Sanchez-Gomez, M.V.; Matute, C.; Alberdi, E. Abeta oligomers promote oligodendrocyte differentiation and maturation via integrin beta1 and Fyn kinase signaling. Cell Death Dis 2019, 10, 445, doi:10.1038/s41419-0191636-8.

54. Prasad, K. AGE-RAGE stress: a changing landscape in pathology and treatment of Alzheimer's disease. Mol Cell Biochem 2019, 459, 95-112, doi:10.1007/s11010-01903553-4.

55. Perrone, A.; Giovino, A.; Benny, J.; Martinelli, F. Advanced Glycation End Products (AGEs): Biochemistry, Signaling, Analytical Methods, and Epigenetic Effects. Oxid Med Cell Longev 2020, 2020, 3818196, doi:10.1155/2020/3818196. 
56. Palimeri, S.; Palioura, E.; Diamanti-Kandarakis, E. Current perspectives on the health risks associated with the consumption of advanced glycation end products: recommendations for dietary management. Diabetes Metab Syndr Obes 2015, 8, 415426, doi:10.2147/DMSO.S63089.

57. Van Puyvelde, K.; Mets, T.; Njemini, R.; Beyer, I.; Bautmans, I. Effect of advanced glycation end product intake on inflammation and aging: a systematic review. Nutr Rev 2014, 72, 638-650, doi:10.1111/nure.12141.

58. Fatoba, O.; Itokazu, T.; Yamashita, T. Complement cascade functions during brain development and neurodegeneration. FEBS J 2021, doi:10.1111/febs.15772.

59. Tenner, A.J. Complement-Mediated Events in Alzheimer's Disease: Mechanisms and Potential Therapeutic Targets. J Immunol 2020, 204, 306-315, doi:10.4049/jimmunol.1901068.

60. Maier, M.; Peng, Y.; Jiang, L.; Seabrook, T.J.; Carroll, M.C.; Lemere, C.A. Complement $\mathrm{C} 3$ deficiency leads to accelerated amyloid beta plaque deposition and neurodegeneration and modulation of the microglia/macrophage phenotype in amyloid precursor protein transgenic mice. J Neurosci 2008, 28, 6333-6341, doi:10.1523/JNEUROSCI.0829-08.2008.

61. Wyss-Coray, T.; Yan, F.; Lin, A.H.; Lambris, J.D.; Alexander, J.J.; Quigg, R.J.; Masliah, E. Prominent neurodegeneration and increased plaque formation in complement-inhibited Alzheimer's mice. Proc Natl Acad Sci U S A 2002, 99, 10837 10842, doi:10.1073/pnas.162350199.

62. Luo, Y.; Hou, W.T.; Zeng, L.; Li, Z.P.; Ge, W.; Yi, C.; Kang, J.P.; Li, W.M.; Wang, F.; Wu, D.B.; et al. Progress in the study of markers related to glioma prognosis. Eur Rev Med Pharmacol Sci 2020, 24, 7690-7697, doi:10.26355/eurrev_202007_22271.

63. Li, S.; Nie, K.; Zhang, Q.; Guo, M.; Qiu, Y.; Li, Y.; Gao, Y.; Wang, L. Macrophage Migration Inhibitory Factor Mediates Neuroprotective Effects by Regulating Inflammation, Apoptosis and Autophagy in Parkinson's Disease. Neuroscience 2019, 416, 50-62, doi:10.1016/j.neuroscience.2019.05.052.

64. Leyton-Jaimes, M.F.; Kahn, J.; Israelson, A. AAV2/9-mediated overexpression of MIF inhibits SOD1 misfolding, delays disease onset, and extends survival in mouse 
models of ALS. Proc Natl Acad Sci U S A 2019, 116, 14755-14760, doi:10.1073/pnas. 1904665116.

65. Leyton-Jaimes, M.F.; Benaim, C.; Abu-Hamad, S.; Kahn, J.; Guetta, A.; Bucala, R.; Israelson, A. Endogenous macrophage migration inhibitory factor reduces the accumulation and toxicity of misfolded SOD1 in a mouse model of ALS. Proc Natl Acad Sci U S A 2016, 113, 10198-10203, doi:10.1073/pnas.1604600113.

66. Dewanjee, S.; Vallamkondu, J.; Kalra, R.S.; John, A.; Reddy, P.H.; Kandimalla, R. Autophagy in the diabetic heart: A potential pharmacotherapeutic target in diabetic cardiomyopathy. Ageing Res Rev 2021, 68, 101338, doi:10.1016/j.arr.2021.101338.

67. Dewanjee, S.; Vallamkondu, J.; Kalra, R.S.; Chakraborty, P.; Gangopadhyay, M.; Sahu, R.; Medala, V.; John, A.; Reddy, P.H.; De Feo, V.; et al. The Emerging Role of HDACs: Pathology and Therapeutic Targets in Diabetes Mellitus. Cells 2021, 10, doi:10.3390/cells 10061340 .

68. Stosic-Grujicic, S.; Saksida, T.; Miljkovic, D.; Stojanovic, I. MIF and insulin: Lifetime companions from common genesis to common pathogenesis. Cytokine 2020, 125, 154792, doi:10.1016/j.cyto.2019.154792.

69. Liang, C.J.; Li, J.H.; Zhang, Z.; Zhang, J.Y.; Liu, S.Q.; Yang, J. Suppression of MIFinduced neuronal apoptosis may underlie the therapeutic effects of effective components of Fufang Danshen in the treatment of Alzheimer's disease. Acta Pharmacol Sin 2018, 39, 1421-1438, doi:10.1038/aps.2017.210.

70. Bacher, M.; Deuster, O.; Aljabari, B.; Egensperger, R.; Neff, F.; Jessen, F.; Popp, J.; Noelker, C.; Reese, J.P.; Al-Abed, Y.; et al. The role of macrophage migration inhibitory factor in Alzheimer's disease. Mol Med 2010, 16, 116-121, doi:10.2119/molmed.2009.00123.

71. Li, S.Q.; Yu, Y.; Han, J.Z.; Wang, D.; Liu, J.; Qian, F.; Fan, G.H.; Bucala, R.; Ye, R.D. Deficiency of macrophage migration inhibitory factor attenuates tau hyperphosphorylation in mouse models of Alzheimer's disease. J Neuroinflammation 2015, 12, 177, doi:10.1186/s12974-015-0396-3.

72. Makhouri, F.R.; Ghasemi, J.B. In Silico Studies in Drug Research Against Neurodegenerative Diseases. Curr Neuropharmacol 2018, 16, 664-725, doi:10.2174/1570159X15666170823095628. 
73. Popp, J.; Bacher, M.; Kolsch, H.; Noelker, C.; Deuster, O.; Dodel, R.; Jessen, F. Macrophage migration inhibitory factor in mild cognitive impairment and Alzheimer's disease. J Psychiatr Res 2009, 43, 749-753, doi:10.1016/j.jpsychires.2008.10.006.

74. Krishnamurthy, S.; Li, J.; Schultz, L.; McAllister, J.P., 2nd. Intraventricular infusion of hyperosmolar dextran induces hydrocephalus: a novel animal model of hydrocephalus. Cerebrospinal Fluid Res 2009, 6, 16, doi:10.1186/1743-8454-6-16.

75. Zachary, I. Signaling mechanisms mediating vascular protective actions of vascular endothelial growth factor. Am J Physiol Cell Physiol 2001, 280, C1375-1386, doi:10.1152/ajpcell.2001.280.6.C1375.

76. Sabbatinelli, J.; Ramini, D.; Giuliani, A.; Recchioni, R.; Spazzafumo, L.; Olivieri, F. Connecting vascular aging and frailty in Alzheimer's disease. Mech Ageing Dev 2021, 195, 111444, doi:10.1016/j.mad.2021.111444.

77. Price, B.R.; Johnson, L.A.; Norris, C.M. Reactive astrocytes: The nexus of pathological and clinical hallmarks of Alzheimer's disease. Ageing Res Rev 2021, 68, 101335, doi:10.1016/j.arr.2021.101335.

78. Kalaria, R.N.; Cohen, D.L.; Premkumar, D.R.; Nag, S.; LaManna, J.C.; Lust, W.D. Vascular endothelial growth factor in Alzheimer's disease and experimental cerebral ischemia. Brain Res Mol Brain Res 1998, 62, 101-105, doi:10.1016/s0169$328 \times(98) 00190-9$.

79. Edmonston, D.; Wolf, M. FGF23 at the crossroads of phosphate, iron economy and erythropoiesis. Nat Rev Nephrol 2020, 16, 7-19, doi:10.1038/s41581-019-0189-5.

80. Cao, R.; Eriksson, A.; Kubo, H.; Alitalo, K.; Cao, Y.; Thyberg, J. Comparative evaluation of FGF-2-, VEGF-A-, and VEGF-C-induced angiogenesis, lymphangiogenesis, vascular fenestrations, and permeability. Circ Res 2004, 94, 664670, doi:10.1161/01.RES.0000118600.91698.BB.

81. Govindpani, K.; McNamara, L.G.; Smith, N.R.; Vinnakota, C.; Waldvogel, H.J.; Faull, R.L.; Kwakowsky, A. Vascular Dysfunction in Alzheimer's Disease: A Prelude to the Pathological Process or a Consequence of It? J Clin Med 2019, 8, doi:10.3390/jcm8050651. 
82. Belluardo, N.; Mudo, G.; Blum, M.; Itoh, N.; Agnati, L.; Fuxe, K. Nicotine-induced FGF-2 mRNA in rat brain is preserved during aging. Neurobiol Aging 2004, 25, 1333 1342, doi:10.1016/j.neurobiolaging.2004.01.002.

83. Chen, S.; Chen, S.T.; Sun, Y.; Xu, Z.; Wang, Y.; Yao, S.Y.; Yao, W.B.; Gao, X.D. Fibroblast growth factor 21 ameliorates neurodegeneration in rat and cellular models of Alzheimer's disease. Redox Biol 2019, 22, 101133, doi:10.1016/j.redox.2019.101133.

84. Levi-Montalcini, R.; Skaper, S.D.; Dal Toso, R.; Petrelli, L.; Leon, A. Nerve growth factor: from neurotrophin to neurokine. Trends Neurosci 1996, 19, 514-520, doi:10.1016/S0166-2236(96)10058-8.

85. Siegel, G.J.; Chauhan, N.B. Neurotrophic factors in Alzheimer's and Parkinson's disease brain. Brain Res Brain Res Rev 2000, 33, 199-227, doi:10.1016/s01650173(00)00030-8.

86. Friedman, W.J.; Black, I.B.; Persson, H.; Ibanez, C.F. Synergistic trophic actions on rat basal forebrain neurons revealed by a synthetic NGF/BDNF chimaeric molecule. Eur J Neurosci 1995, 7, 656-662, doi:10.1111/j.1460-9568.1995.tb00669.x.

87. Du, Y.; Wu, H.T.; Qin, X.Y.; Cao, C.; Liu, Y.; Cao, Z.Z.; Cheng, Y. Postmortem Brain, Cerebrospinal Fluid, and Blood Neurotrophic Factor Levels in Alzheimer's Disease: A Systematic Review and Meta-Analysis. J Mol Neurosci 2018, 65, 289300, doi:10.1007/s12031-018-1100-8.

88. Mitra, S.; Behbahani, H.; Eriksdotter, M. Innovative Therapy for Alzheimer's Disease-With Focus on Biodelivery of NGF. Front Neurosci 2019, 13, 38, doi:10.3389/fnins.2019.00038.

89. Shizuru, J.A.; Negrin, R.S.; Weissman, I.L. Hematopoietic stem and progenitor cells: clinical and preclinical regeneration of the hematolymphoid system. Annu Rev Med 2005, 56, 509-538, doi:10.1146/annurev.med.54.101601.152334.

90. Jin, K.; Peel, A.L.; Mao, X.O.; Xie, L.; Cottrell, B.A.; Henshall, D.C.; Greenberg, D.A. Increased hippocampal neurogenesis in Alzheimer's disease. Proc Natl Acad Sci U S A 2004, 101, 343-347, doi:10.1073/pnas.2634794100.

91. Sopova, K.; Gatsiou, K.; Stellos, K.; Laske, C. Dysregulation of neurotrophic and haematopoietic growth factors in Alzheimer's disease: from pathophysiology to novel 
treatment strategies. Curr Alzheimer Res 2014, 11, 27-39, doi:10.2174/1567205010666131120100743.

92. Boekhoorn, K.; Joels, M.; Lucassen, P.J. Increased proliferation reflects glial and vascular-associated changes, but not neurogenesis in the presenile Alzheimer hippocampus. Neurobiol Dis 2006, 24, 1-14, doi:10.1016/j.nbd.2006.04.017.

93. Laske, C.; Stellos, K.; Stransky, E.; Leyhe, T.; Gawaz, M. Decreased plasma levels of granulocyte-colony stimulating factor (G-CSF) in patients with early Alzheimer's disease. J Alzheimers Dis 2009, 17, 115-123, doi:10.3233/JAD-2009-1017.

94. Laske, C.; Stellos, K.; Stransky, E.; Seizer, P.; Akcay, O.; Eschweiler, G.W.; Leyhe, T.; Gawaz, M. Decreased plasma and cerebrospinal fluid levels of stem cell factor in patients with early Alzheimer's disease. J Alzheimers Dis 2008, 15, 451-460, doi:10.3233/jad-2008-15311.

95. Boese, A.C.; Hamblin, M.H.; Lee, J.P. Neural stem cell therapy for neurovascular injury in Alzheimer's disease. Exp Neurol 2020, 324, 113112, doi:10.1016/j.expneurol.2019.113112.

96. Peng, Z.; Luo, Y.; Xiao, Z.Y. Angiopoietin-1 accelerates Alzheimer's disease via FOXA2/PEN2/APP pathway in APP/PS1 mice. Life Sci 2020, 246, 117430, doi:10.1016/j.lfs.2020.117430.

97. Werman, A.; Werman-Venkert, R.; White, R.; Lee, J.K.; Werman, B.; Krelin, Y.; Voronov, E.; Dinarello, C.A.; Apte, R.N. The precursor form of IL-1alpha is an intracrine proinflammatory activator of transcription. Proc Natl Acad Sci U S A 2004, 101, 2434-2439, doi:10.1073/pnas.0308705101.

98. Tiwari, R.K.; Moin, A.; Rizvi, S.M.D.; Shahid, S.M.A.; Bajpai, P. Modulating neuroinflammation in neurodegeneration-related dementia: can microglial toll-like receptors pull the plug? Metab Brain Dis 2021, 36, 829-847, doi:10.1007/s11011-02100696-6.

99. Gotz, J.; Chen, F.; van Dorpe, J.; Nitsch, R.M. Formation of neurofibrillary tangles in P3011 tau transgenic mice induced by Abeta 42 fibrils. Science 2001, 293, 1491-1495, doi:10.1126/science.1062097. 
100. Busciglio, J.; Lorenzo, A.; Yeh, J.; Yankner, B.A. beta-amyloid fibrils induce tau phosphorylation and loss of microtubule binding. Neuron 1995, 14, 879-888, doi:10.1016/0896-6273(95)90232-5.

101. Dewanjee, S.; Vallamkondu, J.; Kalra, R.S.; Puvvada, N.; Kandimalla, R.; Reddy, P.H. Emerging COVID-19 Neurological Manifestations: Present Outlook and Potential Neurological Challenges in COVID-19 Pandemic. Mol Neurobiol 2021, doi:10.1007/s12035-021-02450-6.

102. Kalra, R.S.; Dhanjal, J.K.; Meena, A.S.; Kalel, V.C.; Dahiya, S.; Singh, B.; Dewanjee, S.; Kandimalla, R. COVID-19, Neuropathology, and Aging: SARS-CoV-2 Neurological Infection, Mechanism, and Associated Complications. Front Aging Neurosci 2021, 13, 662786, doi:10.3389/fnagi.2021.662786.

103. Melov, S.; Adlard, P.A.; Morten, K.; Johnson, F.; Golden, T.R.; Hinerfeld, D.; Schilling, B.; Mavros, C.; Masters, C.L.; Volitakis, I.; et al. Mitochondrial oxidative stress causes hyperphosphorylation of tau. PLoS One 2007, 2, e536, doi:10.1371/journal.pone.0000536.

104. Calabria, L.K.; Vieira da Costa, A.; da Silva Oliveira, R.J.; Ramos Deconte, S.; Nascimento, R.; de Carvalho, W.J.; de Oliveira, V.N.; Arcaro Filho, C.A.; Rezende Alves de Oliveira, L.; Goulart, L.R.; et al. Myosins Are Differentially Expressed under Oxidative Stress in Chronic Streptozotocin-Induced Diabetic Rat Brains. ISRN Neurosci 2013, 2013, 423931, doi:10.1155/2013/423931.

105. Amemori, T.; Jendelova, P.; Ruzicka, J.; Urdzikova, L.M.; Sykova, E. Alzheimer's Disease: Mechanism and Approach to Cell Therapy. Int J Mol Sci 2015, 16, $26417-$ 26451, doi:10.3390/ijms 161125961.

106. Dantzer, R.; Kelley, K.W. Twenty years of research on cytokine-induced sickness behavior. Brain Behav Immun 2007, 21, 153-160, doi:10.1016/j.bbi.2006.09.006.

107. Gutierrez, E.G.; Banks, W.A.; Kastin, A.J. Murine tumor necrosis factor alpha is transported from blood to brain in the mouse. J Neuroimmunol 1993, 47, 169-176, doi:10.1016/0165-5728(93)90027-v.

108. Wang, K.; Wang, H.; Lou, W.; Ma, L.; Li, Y.; Zhang, N.; Wang, C.; Li, F.; Awais, M.; Cao, S.; et al. IP-10 Promotes Blood-Brain Barrier Damage by Inducing Tumor 
Necrosis Factor Alpha Production in Japanese Encephalitis. Front Immunol 2018, 9, 1148, doi:10.3389/fimmu.2018.01148.

109. Pan, W.X., S.; Tu, H.; Kastin, A. J. Cytokines Interact with the Blood-Brain Barrier. In Blood-Brain Barriers: From Ontogeny to Artificial Interfaces.; Wiley: 2006; Volume 1.

110. Uddin, M.S.; Rahman, M.A.; Kabir, M.T.; Behl, T.; Mathew, B.; Perveen, A.; Barreto, G.E.; Bin-Jumah, M.N.; Abdel-Daim, M.M.; Ashraf, G.M. Multifarious roles of mTOR signaling in cognitive aging and cerebrovascular dysfunction of Alzheimer's disease. IUBMB Life 2020, 72, 1843-1855, doi:10.1002/iub.2324.

111. Wimo, A.; Handels, R.; Winblad, B.; Black, C.M.; Johansson, G.; Salomonsson, S.; Eriksdotter, M.; Khandker, R.K. Quantifying and Describing the Natural History and Costs of Alzheimer's Disease and Effects of Hypothetical Interventions. $J$ Alzheimers Dis 2020, 75, 891-902, doi:10.3233/JAD-191055.

112. Numakawa, T.; Odaka, H.; Adachi, N. Actions of Brain-Derived Neurotrophic Factor and Glucocorticoid Stress in Neurogenesis. Int $J$ Mol Sci 2017, 18, doi:10.3390/ijms 18112312 .

113. Permanne, B.; Adessi, C.; Saborio, G.P.; Fraga, S.; Frossard, M.J.; Van Dorpe, J.; Dewachter, I.; Banks, W.A.; Van Leuven, F.; Soto, C. Reduction of amyloid load and cerebral damage in a transgenic mouse model of Alzheimer's disease by treatment with a beta-sheet breaker peptide. FASEB J 2002, 16, 860-862, doi:10.1096/fj.010841fje.

114. Bortolotto, V.; Grilli, M. Every Cloud Has a Silver Lining: Proneurogenic Effects of Abeta Oligomers and HMGB-1 via Activation of the RAGE-NF-kappaB Axis. CNS Neurol Disord Drug Targets 2017, 16, 1066-1079, doi:10.2174/1871527315666160803153459.

115. Konar, A.; Kalra, R.S.; Chaudhary, A.; Nayak, A.; Guruprasad, K.P.; Satyamoorthy, K.; Ishida, Y.; Terao, K.; Kaul, S.C.; Wadhwa, R. Identification of Caffeic Acid Phenethyl Ester (CAPE) as a Potent Neurodifferentiating Natural Compound That Improves Cognitive and Physiological Functions in Animal Models of Neurodegenerative Diseases. Front Aging Neurosci 2020, 12, 561925, doi:10.3389/fnagi.2020.561925. 
116. Martin, I. Resveratrol for Alzheimer's disease? Sci Transl Med 2017, 9, doi:10.1126/scitranslmed.aam6055.

117. Delgado, A.; Cholevas, C.; Theoharides, T.C. Neuroinflammation in Alzheimer's disease and beneficial action of luteolin. Biofactors 2021, 47, 207-217, doi:10.1002/biof.1714.

118. Di Costanzo, A.; Paris, D.; Melck, D.; Angiolillo, A.; Corso, G.; Maniscalco, M.; Motta, A. Blood biomarkers indicate that the preclinical stages of Alzheimer's disease present overlapping molecular features. Sci Rep 2020, 10, 15612, doi:10.1038/s41598-020-71832-y.

119. Biringer, R.G. The Role of Eicosanoids in Alzheimer's Disease. Int J Environ Res Public Health 2019, 16, doi:10.3390/ijerph16142560.

120. Akiyama, H.; Barger, S.; Barnum, S.; Bradt, B.; Bauer, J.; Cole, G.M.; Cooper, N.R.; Eikelenboom, P.; Emmerling, M.; Fiebich, B.L.; et al. Inflammation and Alzheimer's disease. Neurobiol Aging 2000, 21, 383-421, doi:10.1016/s0197-4580(00)00124-x.

121. Letterio, J.J.; Roberts, A.B. TGF-beta: a critical modulator of immune cell function. Clin Immunol Immunopathol 1997, 84, 244-250, doi:10.1006/clin.1997.4409.

122. Kitazawa, M.; Cheng, D.; Tsukamoto, M.R.; Koike, M.A.; Wes, P.D.; Vasilevko, V.; Cribbs, D.H.; LaFerla, F.M. Blocking IL-1 signaling rescues cognition, attenuates tau pathology, and restores neuronal beta-catenin pathway function in an Alzheimer's disease model. J Immunol 2011, 187, 6539-6549, doi:10.4049/jimmunol.1100620.

123. Newcombe, E.A.; Camats-Perna, J.; Silva, M.L.; Valmas, N.; Huat, T.J.; Medeiros, R. Inflammation: the link between comorbidities, genetics, and Alzheimer's disease. $J$ Neuroinflammation 2018, 15, 276, doi:10.1186/s12974-018-1313-3.

124. Zhou, M.; Xu, R.; Kaelber, D.C.; Gurney, M.E. Tumor Necrosis Factor (TNF) blocking agents are associated with lower risk for Alzheimer's disease in patients with rheumatoid arthritis and psoriasis. PLoS One 2020, 15, e0229819, doi:10.1371/journal.pone.0229819.

125. McGeer, P.L.; Schulzer, M.; McGeer, E.G. Arthritis and anti-inflammatory agents as possible protective factors for Alzheimer's disease: a review of 17 epidemiologic studies. Neurology 1996, 47, 425-432, doi:10.1212/wnl.47.2.425. 
126. Nagahara, A.H.; Merrill, D.A.; Coppola, G.; Tsukada, S.; Schroeder, B.E.; Shaked, G.M.; Wang, L.; Blesch, A.; Kim, A.; Conner, J.M.; et al. Neuroprotective effects of brain-derived neurotrophic factor in rodent and primate models of Alzheimer's disease. Nat Med 2009, 15, 331-337, doi:10.1038/nm.1912.

127. Wang, P.; Xie, Z.H.; Guo, Y.J.; Zhao, C.P.; Jiang, H.; Song, Y.; Zhu, Z.Y.; Lai, C.; $\mathrm{Xu}, \mathrm{S} . \mathrm{L} . ; \mathrm{Bi}$, J.Z. VEGF-induced angiogenesis ameliorates the memory impairment in APP transgenic mouse model of Alzheimer's disease. Biochem Biophys Res Commun 2011, 411, 620-626, doi:10.1016/j.bbrc.2011.07.003.

128. Brites, D.; Fernandes, A. Neuroinflammation and Depression: Microglia Activation, Extracellular Microvesicles and microRNA Dysregulation. Front Cell Neurosci 2015, 9, 476, doi:10.3389/fncel.2015.00476.

129. Chong, Z.Z.; Li, F.; Maiese, K. Erythropoietin requires NF-kappaB and its nuclear translocation to prevent early and late apoptotic neuronal injury during beta-amyloid toxicity. Curr Neurovasc Res 2005, 2, 387-399, doi:10.2174/156720205774962683.

130. Decourt, B.; Lahiri, D.K.; Sabbagh, M.N. Targeting Tumor Necrosis Factor Alpha for Alzheimer's Disease. Curr Alzheimer Res 2017, 14, 412-425, doi:10.2174/1567205013666160930110551.

131. Safieh, M.; Korczyn, A.D.; Michaelson, D.M. ApoE4: an emerging therapeutic target for Alzheimer's disease. BMC Med 2019, 17, 64, doi:10.1186/s12916-019-1299-4.

132. Cisbani, G.; Rivest, S. Targeting innate immunity to protect and cure Alzheimer's disease: opportunities and pitfalls. Mol Psychiatry 2021, doi:10.1038/s41380-02101083-4.

133. Du, L.; Zhang, Y.; Chen, Y.; Zhu, J.; Yang, Y.; Zhang, H.L. Role of Microglia in Neurological Disorders and Their Potentials as a Therapeutic Target. Mol Neurobiol 2017, 54, 7567-7584, doi:10.1007/s12035-016-0245-0.

134. Chaudhary, A.; Kalra, R.S.; Huang, C.; Prakash, J.; Kaul, S.C.; Wadhwa, R. 2,3Dihydro-3beta-methoxy Withaferin-A Protects Normal Cells against Stress: Molecular Evidence of Its Potent Cytoprotective Activity. J Nat Prod 2017, 80, 27562760, doi:10.1021/acs.jnatprod.7b00573.

135. Das, B.; Yan, R. A Close Look at BACE1 Inhibitors for Alzheimer's Disease Treatment. CNS Drugs 2019, 33, 251-263, doi:10.1007/s40263-019-00613-7. 
136. Zhang, F.; Zhong, R.J.; Cheng, C.; Li, S.; Le, W.D. New therapeutics beyond amyloid-beta and tau for the treatment of Alzheimer's disease. Acta Pharmacol Sin 2020, doi:10.1038/s41401-020-00565-5.

137. Casali, B.T.; Reed-Geaghan, E.G. Microglial Function and Regulation during Development, Homeostasis and Alzheimer's Disease. Cells 2021, 10, doi:10.3390/cells10040957.

138. Bandyopadhyay, S.; Hartley, D.M.; Cahill, C.M.; Lahiri, D.K.; Chattopadhyay, N.; Rogers, J.T. Interleukin-1alpha stimulates non-amyloidogenic pathway by alphasecretase (ADAM-10 and ADAM-17) cleavage of APP in human astrocytic cells involving p38 MAP kinase. J Neurosci Res 2006, 84, 106-118, doi:10.1002/jnr.20864.

139. Tsai, S.J. Effects of interleukin-1beta polymorphisms on brain function and behavior in healthy and psychiatric disease conditions. Cytokine Growth Factor Rev 2017, 37, 89-97, doi:10.1016/j.cytogfr.2017.06.001.

140. Bakshi, P.; Margenthaler, E.; Reed, J.; Crawford, F.; Mullan, M. Depletion of CXCR2 inhibits gamma-secretase activity and amyloid-beta production in a murine model of Alzheimer's disease. Cytokine 2011, 53, 163-169, doi:10.1016/j.cyto.2010.10.008.

141. Magalhaes, C.A.; Carvalho, M.D.G.; Sousa, L.P.; Caramelli, P.; Gomes, K.B. Alzheimer's disease and cytokine IL-10 gene polymorphisms: is there an association? Arq Neuropsiquiatr 2017, 75, 649-656, doi:10.1590/0004-282X20170110.

142. Ojala, J.O.; Sutinen, E.M. The Role of Interleukin-18, Oxidative Stress and Metabolic Syndrome in Alzheimer's Disease. J Clin Med 2017, 6, doi:10.3390/jcm6050055.

143. Culjak, M.; Perkovic, M.N.; Uzun, S.; Strac, D.S.; Erjavec, G.N.; Leko, M.B.; Simic, G.; Tudor, L.; Konjevod, M.; Kozumplik, O.; et al. The Association between TNFalpha, IL-1 alpha and IL-10 with Alzheimer's Disease. Curr Alzheimer Res 2020, 17, 972-984, doi:10.2174/1567205017666201130092427.

144. Estrada, L.D.; Oliveira-Cruz, L.; Cabrera, D. Transforming Growth Factor Beta Type I Role in Neurodegeneration: Implications for Alzheimer s Disease. Curr Protein Pept Sci 2018, 19, 1180-1188, doi:10.2174/1389203719666171129094937.

145. Joly-Amado, A.; Hunter, J.; Quadri, Z.; Zamudio, F.; Rocha-Rangel, P.V.; Chan, D.; Kesarwani, A.; Nash, K.; Lee, D.C.; Morgan, D.; et al. CCL2 Overexpression in the 
Brain Promotes Glial Activation and Accelerates Tau Pathology in a Mouse Model of Tauopathy. Front Immunol 2020, 11, 997, doi:10.3389/fimmu.2020.00997.

146. Park, J.; Baik, S.H.; Mook-Jung, I.; Irimia, D.; Cho, H. Mimicry of Central-Peripheral Immunity in Alzheimer's Disease and Discovery of Neurodegenerative Roles in Neutrophil. Front Immunol 2019, 10, 2231, doi:10.3389/fimmu.2019.02231.

147. Koper, O.M.; Kaminska, J.; Sawicki, K.; Kemona, H. CXCL9, CXCL10, CXCL11, and their receptor (CXCR3) in neuroinflammation and neurodegeneration. Adv Clin Exp Med 2018, 27, 849-856, doi:10.17219/acem/68846.

148. Lee, S.; Xu, G.; Jay, T.R.; Bhatta, S.; Kim, K.W.; Jung, S.; Landreth, G.E.; Ransohoff, R.M.; Lamb, B.T. Opposing effects of membrane-anchored CX3CL1 on amyloid and tau pathologies via the p38 MAPK pathway. $J$ Neurosci 2014, 34, 12538-12546, doi:10.1523/JNEUROSCI.0853-14.2014.

149. Alvarez, X.A.; Alvarez, I.; Aleixandre, M.; Linares, C.; Muresanu, D.; Winter, S.; Moessler, H. Severity-Related Increase and Cognitive Correlates of Serum VEGF Levels in Alzheimer's Disease ApoE4 Carriers. J Alzheimers Dis 2018, 63, 10031013, doi:10.3233/JAD-160477.

150. Donnini, S.; Cantara, S.; Morbidelli, L.; Giachetti, A.; Ziche, M. FGF-2 overexpression opposes the beta amyloid toxic injuries to the vascular endothelium. Cell Death Differ 2006, 13, 1088-1096, doi:10.1038/sj.cdd.4401803.

151. Cuello, A.C. Editorial: The Involvement of NGF in the Alzheimer's Pathology. Front Neurosci 2019, 13, 872, doi:10.3389/fnins.2019.00872.

152. Shabani, S.F., Y.; Sarkaki, A.; Marda, S. A.; Ahangarpour, A.; Khorsandi, L. The effect of triiodothyronine on the hippocampal long-term potentiation in an animal model of the Alzheimer's disease: The role of BDNF and reelin. Neurology, Psychiatry and Brain Research 2019, 33, 82-88, doi:https://doi.org/10.1016/j.npbr.2019.07.004.

153. Sharif, M.; Noroozian, M.; Hashemian, F. Do serum GDNF levels correlate with severity of Alzheimer's disease? Neurol Sci 2021, 42, 2865-2872, doi:10.1007/s10072-020-04909-1. 
154. Rahi, V.; Jamwal, S.; Kumar, P. Neuroprotection through G-CSF: recent advances and future viewpoints. Pharmacol Rep 2021, 73, 372-385, doi:10.1007/s43440-02000201-3.

155. Dalan, B.; Timirci-Kahraman, O.; Gulec-Yilmaz, S.; Altinkilic, E.M.; Duman, S.; Ayhan, H.; Isbir, T. Potential Protective Role of SDF-1 and CXCR4 Gene Variants in the Development of Dementia. Psychiatr Danub 2020, 32, 92-96, doi:10.24869/psyd.2020.92.

156. Hayashi, S.I.; Rakugi, H.; Morishita, R. Insight into the Role of Angiopoietins in Ageing-Associated Diseases. Cells 2020, 9, doi:10.3390/cells9122636.

157. Schindowski, K.; Belarbi, K.; Buee, L. Neurotrophic factors in Alzheimer's disease: role of axonal transport. Genes Brain Behav 2008, 7 Suppl 1, 43-56, doi:10.1111/j.1601-183X.2007.00378.x.

158. Savaskan, E.; Muller-Spahn, F.; Olivieri, G.; Bruttel, S.; Otten, U.; Rosenberg, C.; Hulette, C.; Hock, C. Alterations in trk A, trk B and trk C receptor immunoreactivities in parietal cortex and cerebellum in Alzheimer's disease. Eur Neurol 2000, 44, 172180, doi:10.1159/000008229.

159. Shen, L.L.; Li, W.W.; Xu, Y.L.; Gao, S.H.; Xu, M.Y.; Bu, X.L.; Liu, Y.H.; Wang, J.; Zhu, J.; Zeng, F.; et al. Neurotrophin receptor p 75 mediates amyloid beta-induced tau pathology. Neurobiol Dis 2019, 132, 104567, doi:10.1016/j.nbd.2019.104567.

\section{Legends to the Figures}

Figure 1. Schematic diagram showing GCSF (Granulocyte colony-stimulating factor) role in promoting neural network survivability via its entry through BBA and regulation of GCSF and LEF1 availability. VEGF increased BBB permeability, however, a defective VEGF expression can promote immunoreactivity and characteristic of AD.

Figure 2. Schematic diagram showing mild cognitive impairment (MCI) characterized by an upregulation of IL1 $\beta$ and $A \beta_{42}$ expressions, which was found to be linked with an upregulation of TNF $\alpha$ and a decrease in TGF $\beta$.

Figure 3. Schematic diagram showing impact of LPS on elicited CCL2 activity that promote Activin A-factor and causes synaptic impairment that subsequently contributes to an aberrant hippocampal plasticity. 
Figure 4. Proinflammatory cytokines and chemoattractant cytokines are key characteristic of neuroinflammation that can be acquired by the activation of microglia and can escalate neurodegeneration. Abnormalities in the TREM2 variant lead to defective microglia activation and decrease in its phagocytic ability.

Figure 5. Schematic diagram showing that an absence of CX3CL1 (chemokine) increases LPS response and leads to an increase in TNF $\alpha$ (proinflammatory cytokine) expression. TNFR1 regulates CPLA2 and could stimulate arachidonate release. Arachidonate release can further led to IL1 release from macrophages under LPS stimulation.

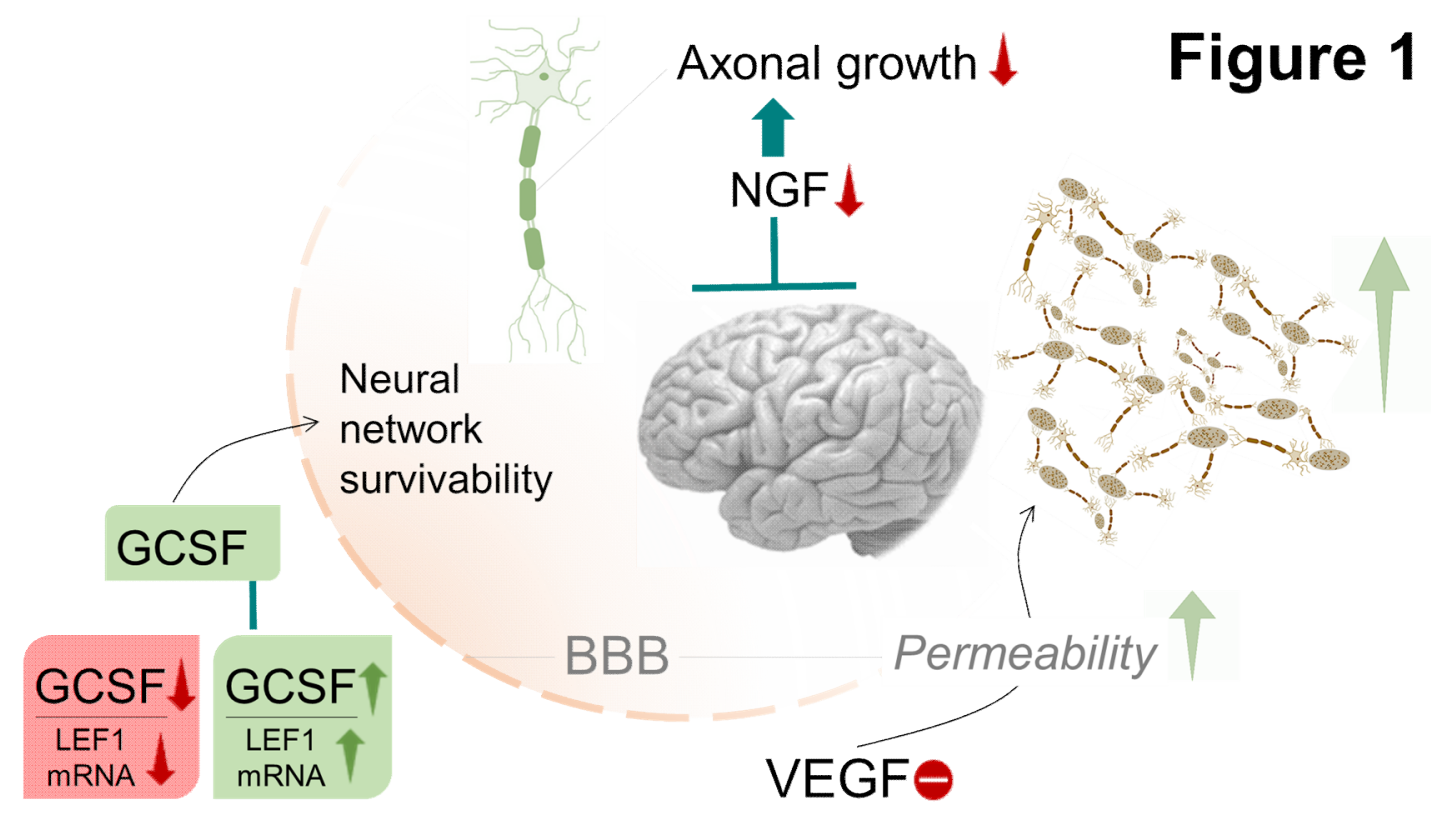




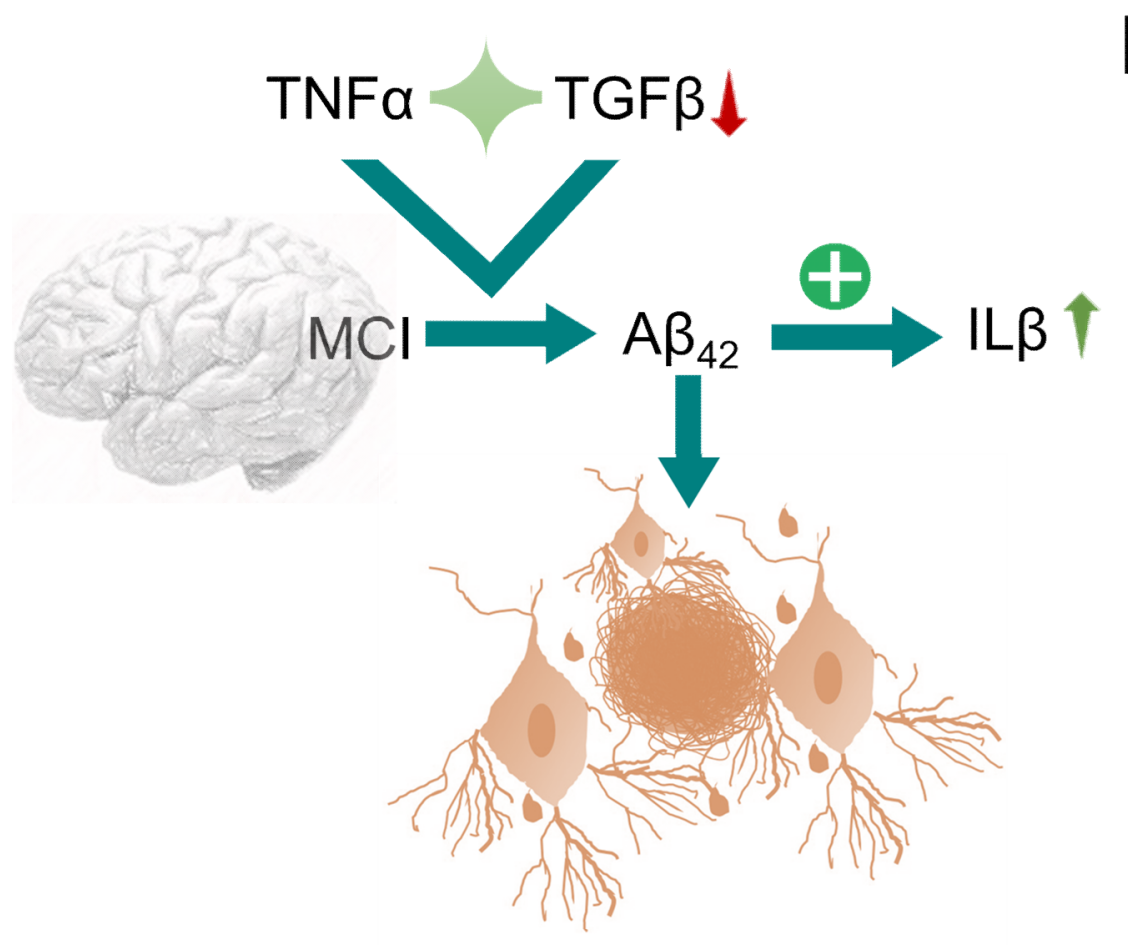

Figure 2

Fipgure 3

(Pro-inflammatory (Chemoattractant

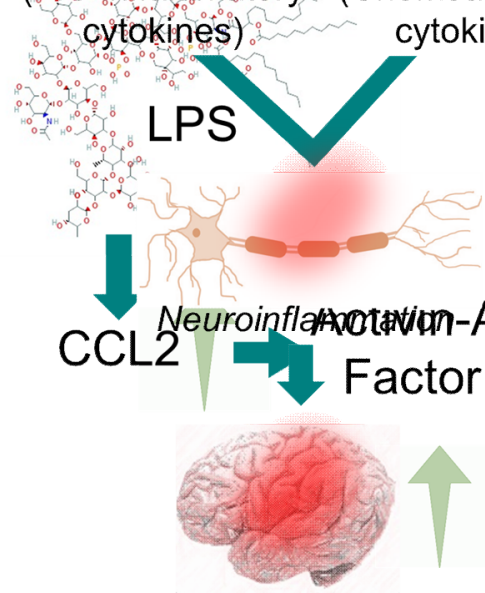

Neurodegeneration

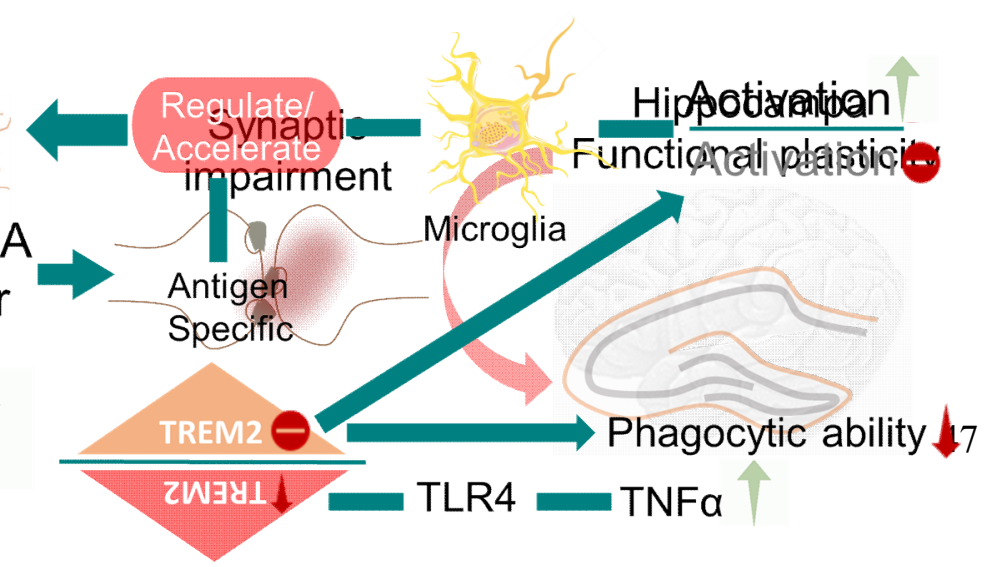




\section{Figure 5}

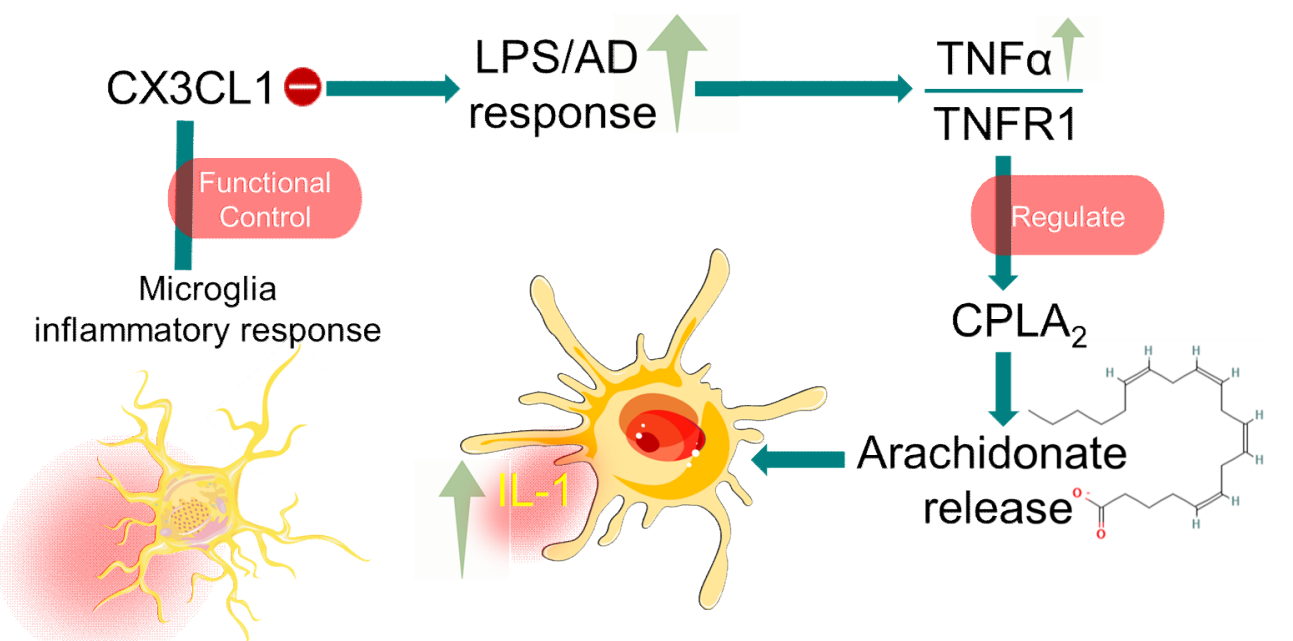

